\title{
The transcriptomic fingerprint of glucoamylase over-expression in Aspergillus niger
}

\author{
Min Jin Kwon ${ }^{1,2}$, Thomas R Jørgensen 1,3, Benjamin M Nitsche ${ }^{1,4}$, Mark Arentshorst ${ }^{1}$, Joohae Park', \\ Arthur FJ Ram ${ }^{1,2^{*}}$ and Vera Meyer ${ }^{1,2,4}$
}

\begin{abstract}
Background: Filamentous fungi such as Aspergillus niger are well known for their exceptionally high capacity for secretion of proteins, organic acids, and secondary metabolites and they are therefore used in biotechnology as versatile microbial production platforms. However, system-wide insights into their metabolic and secretory capacities are sparse and rational strain improvement approaches are therefore limited. In order to gain a genome-wide view on the transcriptional regulation of the protein secretory pathway of A. niger, we investigated the transcriptome of A. niger when it was forced to overexpression the glaA gene (encoding glucoamylase, GlaA) and secrete GlaA to high level.
\end{abstract}

Results: An A. niger wild-type strain and a GlaA over-expressing strain, containing multiple copies of the glaA gene, were cultivated under maltose-limited chemostat conditions (specific growth rate $0.1 \mathrm{~h}^{-1}$ ). Elevated glaA mRNA and extracellular GlaA levels in the over-expressing strain were accompanied by elevated transcript levels from 772 genes and lowered transcript levels from 815 genes when compared to the wild-type strain. Using GO term enrichment analysis, four higher-order categories were identified in the up-regulated gene set: i) endoplasmic reticulum (ER) membrane translocation, ii) protein glycosylation, iii) vesicle transport, and iv) ion homeostasis. Among these, about 130 genes had predicted functions for the passage of proteins through the ER and those genes included target genes of the HacA transcription factor that mediates the unfolded protein response (UPR), e.g. bipA, cIxA, prpA, tigA and pdiA. In order to identify those genes that are important for high-level secretion of proteins by $A$. niger, we compared the transcriptome of the GlaA overexpression strain of $A$. niger with six other relevant transcriptomes of $A$. niger. Overall, 40 genes were found to have either elevated (from 36 genes) or lowered (from 4 genes) transcript levels under all conditions that were examined, thus defining the core set of genes important for ensuring high protein traffic through the secretory pathway.

Conclusion: We have defined the A. niger genes that respond to elevated secretion of GlaA and, furthermore, we have defined a core set of genes that appear to be involved more generally in the intensified traffic of proteins through the secretory pathway of A. niger. The consistent up-regulation of a gene encoding the acetyl-coenzyme A transporter suggests a possible role for transient acetylation to ensure correct folding of secreted proteins.

Keywords: Aspergillus niger, Protein expression, Secretion, HacA, Unfolded protein response, Endoplasmic reticulum, Glucoamylase, Transcriptome

\footnotetext{
* Correspondence: A.F.J.Ram@biology.leidenuniv.nl

'Department Molecular Microbiology and Biotechnology, Institute of Biology Leiden, Leiden University, Sylviusweg 72, 2333 BE, Leiden, The Netherlands

${ }^{2}$ Kluyver Centre for Genomics of Industrial Fermentation, P.O. Box 50572600 GA, Delft, The Netherlands

Full list of author information is available at the end of the article
} 


\section{Background}

Due to its well annotated genome sequence, newly established gene transfer systems, and the availability of high-quality tools for obtaining and evaluating transcriptomic and proteomic data, Aspergillus niger has become a model fungus for industrially exploited filamentous fungi [1-4]. Its impressive natural capacity to secrete high amounts of hydrolytic proteins into the environment combined with its ability to synthesize and secrete various organic acids makes it highly suitable for the production of various food ingredients, pharmaceuticals, and industrial enzymes $[1,2,5]$. As it is also capable of efficiently degrading plant-derived polysaccharides such as starch, cellulose, hemicellulose, pectin, and inulin, the biotechnological importance of $A$. niger will probably rise even more in the near future. For example, $A$. nigerderived (hemi)cellulases might be used to improve the efficiency of the saccharification process of secondgeneration feedstock used for bioethanol production $[3,6]$.

To analyze and eventually control the secretory capabilities of $A$. niger, several attempts have been undertaken to identify the key players and regulatory mechanisms involved in protein secretion. For example, galacturonic acid, xylose, and maltose were shown to induce expression of secretory proteins, including pectinolytic, (hemi)cellulolytic and glucan-hydrolyzing enzymes, respectively, whereas sorbitol acts as a repressing carbon source [7-10]. Xylose is the main inducer of XlnR, the master transcription factor that regulates expression of all major enzymes involved in the degradation of (hemi) cellulose [9-11]. Among those, endoxylanase (XynB) and ferulic acid esterase (FaeA) are the most abundant, secreted proteins of $A$. niger [10]. When starch or maltose are used as carbon source, the synthesis of amylolytic enzymes is induced, a step that is mediated by the transcription factor AmyR. The most abundant enzyme secreted under these conditions is a glucan 1,4- $\alpha$-glucosidase (glucoamylase, GlaA), which is an exo-enzyme that releases glucose from the non-reducing end of starch or maltose and accounts for more than $50 \%$ of the extracellular proteome [10]. Induction of extracellular hydrolytic enzymes is thus mainly regulated at the transcriptional level in $A$. niger, and either repressed by carbon catabolite repression via CreA [12] or activated by AmyR or XlnR depending on the presence of maltose or xylose, respectively [13].

$A$. niger proteins and enzymes destined for secretion into the culture medium follow the secretory pathway. The journey of secretory proteins starts with protein translocation into the lumen of the endoplasmic reticulum (ER) via a translocon that forms a channel through the ER membrane [14]. In the ER lumen, several ER-resident chaperones and foldases, including the binding protein (BipA), protein disulfide isomerase (PdiA), and calnexin (ClxA), assist secretory proteins in proper folding [15]. Most secretory proteins become glycosylated in the ER, both through the attachment of a conserved, pre-assembled oligosaccharide to specific asparagine residues ( $N$-glycosylation) and by the initiation of $\mathrm{O}$-glycosylation of serine and threonine residues. After proper folding and glycosylation, secretory proteins are packed into COPII-coated vesicles and transported to the Golgi complex, where protein glycosylation is completed, and subsequently through another vesicle-mediated process delivered to the cell surface where the vesicles release their cargo into the periplasmic region. High protein flux through the ER or expression of heterologous proteins can result in the accumulation of misfolded proteins. This misfolding, however, is recognized by a quality control system known as ER-associated degradation (ERAD). The aim of ERAD is to direct misfolded proteins to the cytosol where they become degraded by the proteasome. In addition, another cellular protein quality system, the unfolded protein response (UPR), is induced, which aims at proper refolding of misfolded proteins via induced expression of chaperones and foldases [5,16]. For this purpose, the UPR transcription factor HacA becomes activated via splicing of an unconventional 20-nt intron out of the hacA mRNA. This subsequently facilitates translation of hacA mRNA and formation of HacA, which in turn induces transcription of a number of UPR target genes including bipA, which encodes the major ER chaperone protein, and $p d i A$, which encodes for protein disulfide isomerase $[17,18]$. Hence, both ERAD and UPR are crucial for effective functioning of the secretory pathway - not only in filamentous fungi but also in yeasts and mammals [19-22].

Interestingly, the UPR can be viewed as a general response of $A$. niger, which becomes activated when the secretion machinery becomes challenged by metabolic changes or ER stress conditions. For example, transcript levels of UPR genes become strongly enhanced, when $A$. niger is exposed to the reducing compound dithiothreitol (DTT), which blocks the formation of disulfide bridges, or to tunicamycin, which inhibits $N$-glycosylation, especially when forced to express heterologous proteins or when cultivated in carbon sources, which differentially induce expression and secretion of homologous proteins $[18,23,24]$. These observations suggest that the UPR functions as a homeostatic control mechanism that allows $A$. niger to flexibly adapt its protein secretion capacity to change in environmental conditions.

In this study, we investigated the transcriptomic fingerprint of $A$. niger when forced to overexpress and secrete a specific hydrolytic enzyme. We chose glucoamylase (GlaA) as a model enzyme, because it is a 
naturally highly abundant and secreted enzyme used in the food industry [25]. For comparison, we used two strains, a wild-type strain expressing a single copy of the glaA gene, and a mutant strain expressing multiple copies of glaA. In order to reduce the number of conflicting variables, such as changes in growth rates and fluctuations in environmental conditions, maltose-limited chemostat cultures were used. Maltose was selected as a carbon source to transcriptionally induce expression of the glaA gene. Physiological and transcriptomic data were collected from both wild-type and overexpressing strains and analyzed to identify the glaA-specific overexpression transcriptome. Finally, we compared these global transcriptional changes with previously published transcriptomic data related to secretion stress in $A$. niger. This analysis allowed us to distinguish conditionspecific responses from general transcriptomic responses of $A$. niger that are important to overcome different triggers of secretion stress. We could identify a core set of 40 genes whose expression is key to ensure high protein fluxes through the secretory route of $A$. niger, independently of the cause of the secretion stress.

\section{Results and discussion}

\section{Growth physiology of maltose-limited chemostat}

\section{cultures of A. niger}

In order to identify the transcriptomic adaptations of $A$. niger to forced overproduction of GlaA, we compared the transcriptomes of chemostat-grown cultures of strain B36 (overproducing strain) and wild-type strain N402 (reference strain). Strain B36 was selected as GlaA overproducer, because it is reported to contain multiple copies of the glaA gene at chromosome V [26,27].

Maltose-limited chemostat cultures were used to induce expression of the glaA gene, to control the specific growth rate and to obtain highly reproducible data due to well-defined steady state conditions. Initial chemostat experiments were conducted using three different dilution rates $\left(\mathrm{D}=0.05,0.1\right.$, and $0.15 \mathrm{~h}^{-1}$ ); however, steady state conditions for both strains were only reached at $\mathrm{D}=0.1 \mathrm{~h}^{-1}$. At a higher dilution rate $\left(\mathrm{D}=0.15 \mathrm{~h}^{-1}\right)$, N402 reached a steady state, but the B36 strain was washed out before reaching a steady state. Although the morphology of the N402 strain at the lowest dilution rate $\left(\mathrm{D}=0.05 \mathrm{~h}^{-1}\right)$ was similar to the higher dilution rates, and no sign of mycelial aggregation was apparent (data not shown), N402 was not able to reach a steady state at this dilution rate. Maltose-limited chemostat cultures were therefore run in triplicate at $\mathrm{D}=0.1 \mathrm{~h}^{-1}$ for both strains. The cultures were highly reproducible and gave rise to homogenous cultures of dispersed mycelial morphologies (Figure 1, Table 1, and data not shown). The initial batch cultivation (duration about $30 \mathrm{~h}$ ) was followed by approximately $50 \mathrm{~h}$ of continuous cultivation. After four volume changes $\left(4 \mathrm{x} \mathrm{D}^{-1}\right)$, the cultures reached a steady state as reflected by a constant alkali addition rate and constant $\mathrm{CO}_{2}, \mathrm{O}_{2}$, and biomass concentrations (Figure 1 and data not shown). Biomass concentrations for both strains stabilized at about $4 \mathrm{~g} \mathrm{~kg}^{-1}$ with a small relative standard deviation (RSD) (approx. 0.002 for N402 and 0.02 for B36). In both strains, the respiratory quotient (RQ) was lower than 1 , probably due to high production of organic acids in parallel to GlaA secretion. Notably, the RQ value calculated for B36 cultures was slightly but significantly lower than the RQ value obtained for N402 cultures (Table 1), suggesting that protein and acid production is somewhat higher in B36 compared to N402. In agreement, the carbon concentration in culture filtrates obtained from steady state samples was also higher in B36 compared to N402 (data not shown) and the specific productivity of extracellular protein ( $\mathrm{q}_{\text {protein-EC}}$ ) was five- to six-fold higher in B36 than N402, demonstrating that B36 indeed secretes more protein than the wild-type strain.
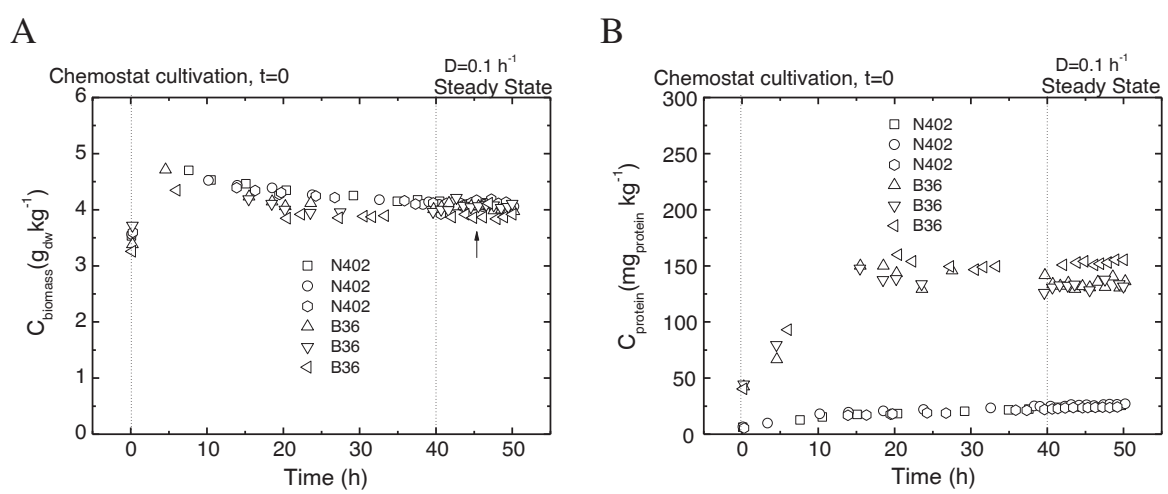

Figure 1 Growth profiles (A) and extracellular protein production (B) of N402 and B36. The growth curves presented are based on (A) dry-weight biomass concentration and on (B) total protein concentration in culture filtrates. An arrow indicates RNA sampling for transcriptomics. All six independent cultures are shown. 
Table 1 Physiology of N402 and B36 in chemostat cultures

\begin{tabular}{|c|c|c|c|c|c|c|c|c|}
\hline & $\begin{array}{c}C_{\text {biomass }} \\
\left(g_{\text {DW }} \mathrm{kg}^{-1}\right)\end{array}$ & $\begin{array}{c}Y_{x / s} \\
\left(g_{D w} g_{\text {maltose }}^{-1}\right) \\
\end{array}$ & $\begin{array}{c}Y_{x / c} \\
\left(g_{D W} g_{\text {carbon }}^{-1}\right) \\
\end{array}$ & $\begin{array}{c}\mathrm{qcO}^{\mathrm{co}} \\
\left(\mathrm{mmol} \mathrm{g}^{-1} \mathrm{~h}^{-1}\right)\end{array}$ & $\begin{array}{c}\mathrm{q}_{\mathrm{o2}} \\
\left(\mathrm{mmol} \mathrm{g}^{-1} \mathrm{~h}^{-1}\right)\end{array}$ & $\mathrm{RQ}$ & $\begin{array}{c}\mathrm{q}_{\text {protein-EC }} \\
\left(\mathrm{mg} \mathrm{g}^{-1} \mathrm{~h}^{-1}\right)\end{array}$ & $\begin{array}{c}\text { C-recovery } \\
(\%)\end{array}$ \\
\hline N402 & $4.09 \pm 0.01$ & $0.49 \pm 0.02$ & $1.22 \pm 0.05$ & $2.11 \pm 0.05$ & $2.38 \pm 0.06$ & $0.88 \pm 0.03$ & $0.60 \pm 0.03$ & $92 \pm 0.8$ \\
\hline B36 & $4.01 \pm 0.09$ & $0.47 \pm 0.01$ & $1.17 \pm 0.03$ & $2.05 \pm 0.07$ & $2.51 \pm 0.14$ & $0.82 \pm 0.03$ & $3.49 \pm 0.37$ & $89 \pm 0.3$ \\
\hline
\end{tabular}

Steady state results of maltose-limited chemostat cultures. Mean values \pm standard deviations are given for N402 and B36 from triplicate independent steady-state cultures. Bold letters indicate significant differences based on a two tailed t-test $(p<0.001)$. $C_{b i o m a s s}$ dry weight of biomass concentration; $Y_{x / s}$ and $\mathrm{Y}_{\mathrm{x} / \mathrm{c}}$, growth yield on substrate and carbon; $\mathrm{q}_{\mathrm{cO} 2}$ and $\mathrm{q}_{\mathrm{O} 2}$, specific carbon dioxide evolution rate and oxygen consumption rate; $\mathrm{RQ}$, respiratory quotient; $\mathrm{q}_{\text {protein-EC, }}$ specific extracellular protein production rate; C-recovery, carbon recovery.

\section{Protein secretion and glucoamylase production during steady state}

The GlaA overproducer strain B36 was previously estimated to contain about 80 copies of the glaA gene as inferred from Southern analysis [26]. As multiple gene copies can cause frequent recombination in $A$. niger resulting in genetic instability and loss of glaA copies [27], we decided to re-determine the number of glaA copies present in B36 using quantitative real time PCR (qPCR). As summarized in Table 2, B36 contains about 32 glaA gene copies based on the fact that N402 contains only a single copy of glaA [3]. We also determined glaA mRNA levels by qPCR and observed that glaA transcript levels in B36 were about seven times higher compared to N402. Consistent with this observation, under steady state conditions extracellular GlaA production in B36 was about seven- to eight-fold higher than in $\mathrm{N} 402$ as estimated by Western analysis and measuring glucoamylase activity (Table 2). These data confirm previous observations that the amount of GlaA produced correlates well with the amount of glaA mRNA but is not proportional to the number of glaA gene copies, a well-known phenomenon in filamentous fungi, where protein overproduction is often limited at the transcriptional level [13,27]. It should be noted, however, that the increased glucoamylase production in the B36 strain is still significantly lower compared to industrial strains which produce glucoamylase up to 30 gram/liter [28].

Table 2 Glucoamylase assessments in N402 (wild-type strain) and B36 (overexpressing strain)

\begin{tabular}{lcc}
\hline & $\mathbf{N 4 0 2}$ & B36 \\
\hline glucoamylase gene copy number $^{\mathrm{a}}$ & 1 & $32 \pm 5$ \\
glucoamylase transcripts level $^{\mathrm{a}}$ & 1 & $6.9 \pm 0.9$ \\
glucoamylase protein detection $\left(\mathrm{g}^{-1}\right)^{\mathrm{b}}$ & 1 & $8.3 \pm 1.8$ \\
${\left.\text { glucoamylase activity }(\mathrm{U} \mathrm{g})^{-1}\right)^{\mathrm{c}}}$ & $154 \pm 68$ & $1057 \pm 398$ \\
\hline
\end{tabular}

Glucoamylase was assessed using steady-state samples. Mean values \pm standard deviations for $\mathrm{N} 402$ and B36 were calculated from triplicate measurements of respective triplicate steady-state samples. ${ }^{\mathrm{a}} \mathrm{Glucoamylase}$ gene copy number and relative glucoamylase transcripts level were assessed by qPCR using genomic DNA and CDNA as templates. ${ }^{b}$ Western blot analysis of glucoamylase protein. Culture filtrate samples corrected for equal amounts of biomass were loaded onto SDS-PAGE. The amount of glucoamylase protein was represented as relative values based on N402. 'Glucoamylase activity was determined by measuring liberated glucose from starch.

\section{The GlaA-overexpression transcriptome}

RNA samples for microarray analysis were taken from triplicate steady-state cultures of both strains. The average RSD of all genes expressed was about 0.06, indicating high reproducibility of all six chemostat cultures and transcript profiles. The expression of 1,587 genes out of 14,165 A. niger genes was changed: 772 displayed increased expression levels in the strain B36, and 815 genes were down-regulated in B36 (significance: FDR, $q$ value $<0.005)$. Although the majority of differentially expressed genes (1,280 genes) showed fold-changes in gene expression $<2$, these values are considered to be significant in view of the identical culture conditions used, the identical specific growth rates of both strains during steady state conditions, and the stringent statistical analysis of the data. A comprehensive list of all differentially expressed genes is depicted in Additional file 1.

An enrichment analysis was performed to identify gene ontology (GO) terms which were over-represented in the differentially expressed gene set. We used the recently published improved $\mathrm{GO}$ annotation tool for A. niger (Fisher's exact test Gene Ontology annotation tool, FetGOat [29]), an open source tool accessible at http://www.broadinstitute.org/fetgoat/index.html. GO terms (up- or down-regulated) with FDR values $<0.05$ were defined as over-represented. Overall, 129 enriched GO terms were identified among the differentially expressed gene set, 54 of which belonged to 'biological processes' (BP), 63 to 'cellular components' (CC) and 12 to 'molecular functions' (MF). The corresponding network maps and gene lists are depicted in the Additional file 2 and Additional file 3.

\section{Predicted up- and down-regulated biological processes inferred from the GlaA-overexpression transcriptome}

In order to deduce biological information out of the GO term enrichment analysis, we focused on the BP gene list and removed redundant and less detailed annotations. Among the remaining GO terms in the up-regulated gene set, the following four higher-order categories were identified: i) translocation, ii) protein glycosylation, iii) vesicle transport, and iv) ion homeostasis (see Additional file 4). The translocation category included GO terms 
such as 'posttranslational protein targeting to membrane,' 'SRP-dependent co-translational protein targeting to membrane', 'translocation', and 'protein targeting to ER'. The protein glycosylation category included the GO terms 'related to glycosylation', 'protein N-linked glycosylation', 'oligosaccharide biosynthetic process', 'dolichol-linked oligosaccharide biosynthetic process', and 'oligosaccharide-lipid intermediate biosynthetic process'. The vesicle transport category included the GO terms 'vesicle-mediated transport,' 'COPII-coated vesicle budding, 'membrane budding', 'vesicle organization', 'vesicle coating,' vesicle targeting (rough ER to cis-Golgi)', 'COPII vesicle coating', and 'retrograde vesicle-mediated transport (Golgi to ER)'. The last category, ion homeostasis, contained GO terms involved in iron, calcium, and zinc homeostasis (e.g. 'iron homeostasis', 'inorganic cation homeostasis', 'cellular response to iron starvation,' and 'ion transport', see Additional file 4).

As three out of the four major categories were related to the secretory pathway, the corresponding genes lists were examined in more detail. The expression of at least 130 predicted secretory pathway genes were changed in the GlaA-overexpressing strain B36 (Table 3). Importantly, this set of genes is causatively linked to GlaA overexpression and does not depend on the growth rate or the carbon source, because both strains were in steady state at the same specific growth rate in maltose-limited chemostat cultures. Only 16 of the 130 genes were down-regulated, indicating that the capacity of the protein secretion machinery is increased compared to the wild-type situation. Among the secretory pathwayrelated genes, the majority of the induced genes belonged to ER-related processes, including translocation into the ER, protein folding, glycosylation, ERAD, UPR, and COPI- and COPII-mediated transport processes (Table 3). Notably, the gene with the most significantly increased transcript level in B36 was the bipA gene $\left(\mathrm{FDR}, 1.1 \times 10^{-7}\right.$ ), which is under transcriptional control of HacA [17], and encodes the main chaperone in the ER and is thus important for protein overproduction in A. niger [30]. The increased expression of bipA gene in the B36 strain was previously reported by Northern blot analysis in a shake flask culture [31]. In agreement, other important HacA-dependent ER chaperones and foldases such as $\operatorname{clx} A, \operatorname{prp} A, \operatorname{tig} A$, and $p \operatorname{diA}$ (Table 3) were also significantly higher expressed in B36 [17].

As up-regulation of these genes pointed towards slow or aberrant folding of GlaA and thus induction of UPR in strain B36, we tested whether the central activation mechanism of UPR, the stress-induced splicing of hacA mRNA and thus increased expression of HacA target genes [32], was induced in strain B36. The ratio of spliced to unspliced hacA mRNA was indeed considerably higher in strain B36 (Figure 2A), demonstrating that forced overexpression of GlaA provokes ER stress, leading to an UPR in order to ensure proper folding and secretion of GlaA. Figure $2 \mathrm{~B}$ shows that this response is appropriate and sufficient for $A$. niger, because strain B36 is better adapted to grow on starch compared to the wild-type strain. Interestingly, starch- and maltoseresponsive genes such as the transcription factor AmyR and AmyR-dependent hydrolase genes [33] are down regulated in B36 except glaA (Table 4). As previously suggested, a possible explanation for the reduced expression could be the titration of the AmyR transcription factor due to the high number of glaA promoter copies in this strain [27]. Alternatively, the biosynthesis of an inducer through one of the enzymes under control of AmyR might be reduced. Lower inducer levels could then lead to lower levels of active AmyR transcription factor, leading to a negative feedback loop. Downregulation of AmyR targets (except for glaA, Table 4) could also be explained by the RESS (repression under secretion stress) phenomenon, described for Trichoderma reesei [19,34] and Arabidopsis thaliana [35], and predicted for $A$. niger [36]. RESS is a transcriptional feedback mechanism that is activated in response to impairment of protein folding or transport and aims at lowering the protein load in the secretory route when ER stress conditions are sensed [34]. As we have observed that GlaA overexpression induces a mild UPR (Figure 2A), we propose that down-regulation of AmyR and its target genes reflects a negative feedback mechanism similar to RESS in $T$. reesei.

Notably, enriched GO terms of the 'ion homeostasis' category indicated an increased demand for iron, calcium, and zinc. In the context of increased fluxes of GlaA through the secretory pathway in strain B36, several explanations are conceivable. First, the mature GlaA protein contains nine cysteine residues, eight of which are involved in disulfide bridge formation $[37,38]$. Hence, in B36 there is an increased demand for disulfide bond formation, which requires increased activity of protein disulfide isomerases. Increased amounts of PdiA, however, might result in sequestration of zinc ions in the ER $[38,39]$, thus preventing it from binding to other proteins and causing a cellular shortage of zinc. Second, chaperones such as ClxA needs calcium as co-factor [40], hence enhanced expression of $\operatorname{clx} A$ in B36 calls for higher calcium concentrations in the ER. Third, calcium is of general importance for vesicle fusions and the function of the ER and Golgi $[41,42]$. Hence, the cells have to mobilize calcium from internal or external stores to ensure higher fluxes through the secretory pathway in B36. Finally, the activity of GlaA is known to be positively affected by the presence of $\mathrm{Mn}^{2+}, \mathrm{Ca}^{2+}$, and $\mathrm{Fe}^{2+}$ ions [25], which are also required for many other protein activities including heme or iron-sulfur-cluster (Fe-S) 
Table 3 Differential expression of genes encoding secretory pathway related proteins

\begin{tabular}{|c|c|c|c|c|}
\hline DSM code & DSM annotation & Fold-change B36/N402 & $\mathbf{P}$ & FDR \\
\hline \multicolumn{5}{|l|}{ Protein folding } \\
\hline An02g14800* & protein disulfide isomerase $\mathrm{A} p d i A-A$. niger & 1.72 & $5.98 \mathrm{E}-08$ & 3.43E-06 \\
\hline An18g02020* & disulfide isomerase tigA - A. niger & 1.89 & $1.61 \mathrm{E}-08$ & 1.17E-06 \\
\hline An01g04600* & PDI related protein A prpA - A.niger & 2.08 & 2.21E-09 & 2.40E-07 \\
\hline An16g07620* & $\begin{array}{l}\text { strong similarity to endoplasmic reticulum } \\
\text { oxidising protein Ero1 - S. cerevisiae }\end{array}$ & 1.97 & $1.02 \mathrm{E}-08$ & 8.15E-07 \\
\hline An 18g04260* & $\begin{array}{l}\text { similarity to secreted protein HNTME13 from } \\
\text { patent WO9839446-A2 - H. sapiens }\end{array}$ & 2.46 & $1.06 \mathrm{E}-09$ & $1.28 \mathrm{E}-07$ \\
\hline An18g06470* & $\begin{array}{l}\text { strong similarity to DnaJ-like protein } \\
\text { MTJ1 - Mus musculus }\end{array}$ & 1.48 & $1.34 \mathrm{E}-06$ & $3.70 \mathrm{E}-05$ \\
\hline An05g00880* & $\begin{array}{l}\text { strong similarity to dnaJ protein homolog } \\
\text { Scj } 1-\text { S. cerevisiae }\end{array}$ & 1.79 & 1.02E-07 & 5.04E-06 \\
\hline An01g08420* & $\begin{array}{l}\text { strong similarity to calcium-binding protein } \\
\text { precursor } \mathrm{cl} \times 1 \mathrm{p}-\mathrm{S} \text {. pombe }\end{array}$ & 2.42 & $8.96 \mathrm{E}-10$ & 1.13E-07 \\
\hline An04g02020* & strong similarity to cyclophilin cypB - A. nidulans & 1.69 & 1.19E-07 & $5.60 \mathrm{E}-06$ \\
\hline An01g06670* & $\begin{array}{l}\text { strong similarity to peptidyl-prolyl isomerase } \\
\text { FKBP-21 - N. crassa }\end{array}$ & 1.66 & 4.71E-07 & 1.57E-05 \\
\hline An11g04180* & dnaK-type molecular chaperone bipA - A. niger & 2.32 & 8.63E-10 & 1.11E-07 \\
\hline An01g13220* & $\begin{array}{l}\text { strong similarity to } 150 \mathrm{kDa} \text { oxygen regulated } \\
\text { protein ORP150 - Rattus norvegicus }\end{array}$ & 2.26 & $1.34 \mathrm{E}-09$ & $1.58 \mathrm{E}-07$ \\
\hline \multicolumn{5}{|c|}{ Signal recognition/cleavage } \\
\hline An04g06890 & $\begin{array}{l}\text { similarity to } 72-k D \text { protein of the signal recognition } \\
\text { particle SRP72 - Canis lupus }\end{array}$ & 1.33 & 1.14E-04 & 1.37E-03 \\
\hline An15g06470* & $\begin{array}{l}\text { similarity to signal sequence receptor alpha } \\
\text { chain - Canis lupus }\end{array}$ & 1.86 & 4.49E-08 & $2.72 \mathrm{E}-06$ \\
\hline An01g00560* & $\begin{array}{l}\text { strong similarity to signal peptidase subunit } \\
\text { Sec11 - S. cerevisiae }\end{array}$ & 1.84 & $5.70 \mathrm{E}-07$ & 1.84E-05 \\
\hline An $16 \mathrm{~g} 07390^{*}$ & $\begin{array}{l}\text { strong similarity to endoplasmatic reticulum } \\
\text { signal peptidase subunit Spc2 - S. cerevisiae }\end{array}$ & 1.90 & 7.99E-09 & $6.74 \mathrm{E}-07$ \\
\hline An09g05420* & similarity to signal peptidase subunit Spc3 - S. cerevisiae & 1.99 & $6.90 \mathrm{E}-09$ & $6.03 \mathrm{E}-07$ \\
\hline \multicolumn{5}{|c|}{ Translocation into ER } \\
\hline An03g04340* & $\begin{array}{l}\text { strong similarity to ER membrane translocation } \\
\text { facilitator Sec61 - Yarrowia lipolytica }\end{array}$ & 1.68 & $9.76 \mathrm{E}-08$ & 4.90E-06 \\
\hline An01g03820 & $\begin{array}{l}\text { strong similarity to ER protein-translocation complex } \\
\text { subunit Sbh2 - S. cerevisiae }\end{array}$ & 1.62 & 2.60E-06 & $6.33 \mathrm{E}-05$ \\
\hline An01g11630* & $\begin{array}{l}\text { strong similarity to translocation complex component } \\
\text { Sss1 - S. cerevisiae }\end{array}$ & 1.71 & 1.88E-07 & $8.11 \mathrm{E}-06$ \\
\hline An02g01510* & $\begin{array}{l}\text { strong similarity to component of the endoplasmic } \\
\text { reticulum protein translocation machinery } \\
\text { Sec62 - S. cerevisiae }\end{array}$ & 1.57 & $7.50 \mathrm{E}-06$ & 1.49E-04 \\
\hline An01g13070* & $\begin{array}{l}\text { strong similarity to signal recognition particle receptor } \\
\text { Sec63 - S. cerevisiae }\end{array}$ & 2.02 & 2.17E-08 & 1.47E-06 \\
\hline An $16 \mathrm{~g} 08830^{*}$ & $\begin{array}{l}\text { strong similarity to component of ER protein-translocation } \\
\text { subcomplex Sec71 from patent WO9949028-A1 - S. cerevisiae }\end{array}$ & 1.80 & 3.47E-08 & 2.17E-06 \\
\hline An15g01670 & $\begin{array}{l}\text { strong similarity to signal sequence receptor alpha } \\
\text { subunit SRP101 - Yarrowia lipolytica }\end{array}$ & 1.29 & $1.14 \mathrm{E}-04$ & 1.37E-03 \\
\hline An05g00140* & $\begin{array}{l}\text { similarity to signal recognition particle receptor beta } \\
\text { chain Srp102 - S. cerevisiae }\end{array}$ & 1.39 & $2.57 \mathrm{E}-05$ & 4.16E-04 \\
\hline \multicolumn{5}{|l|}{ Glycosylation } \\
\hline An02g07650 & strong similarity to phosphoglucomutase pgmB $-A$. nidulans & 0.80 & $5.29 \mathrm{E}-04$ & 4.81E-03 \\
\hline An03g05940* & strong similarity to glutamine-fructose-6-phosphate & 0.66 & $2.20 \mathrm{E}-06$ & $5.58 \mathrm{E}-05$ \\
\hline
\end{tabular}


Table 3 Differential expression of genes encoding secretory pathway related proteins (Continued)

\begin{tabular}{|c|c|c|c|c|}
\hline An04g04990* & $\begin{array}{l}\text { strong similarity to mannose-1-phosphate guanyltransferase } \\
\text { MPG1 - Trichoderma reesei }\end{array}$ & 1.46 & $1.44 \mathrm{E}-05$ & 2.57E-04 \\
\hline An11g02380* & $\begin{array}{l}\text { strong similarity to GTP:alpha-D-mannose-1-phosphate } \\
\text { guanylyltransferase MPG1 - Hypocrea jecorina }\end{array}$ & 1.35 & 5.47E-05 & 7.67E-04 \\
\hline An02g08660 & $\begin{array}{l}\text { strong similarity to hypothetical protein } \\
\text { H04M03.4 - Caenorhabditis elegans }\end{array}$ & 1.25 & $2.90 \mathrm{E}-04$ & 2.91E-03 \\
\hline An03g06940* & $\begin{array}{l}\text { strong similarity to UPD-GlcNAc transporter } \\
\text { MNN2-2 - Kluyveromyces lactis }\end{array}$ & 1.35 & $2.72 \mathrm{E}-05$ & 4.38E-04 \\
\hline An02g14560* & oligosaccharyltransferase alpha subunit OstA - A. niger & 2.05 & $2.27 \mathrm{E}-09$ & 2.40E-07 \\
\hline An07g04190* & $\begin{array}{l}\text { strong similarity to dolichyl-diphospho-oligosaccharide- } \\
\text { protein glycosyltransferase } 48 \mathrm{kD} \text { chain DDOST - Gallus gallus }\end{array}$ & 1.69 & $1.03 \mathrm{E}-07$ & $5.04 \mathrm{E}-06$ \\
\hline An18g03920* & $\begin{array}{l}\text { strong similarity to defender against apoptotic cell } \\
\text { death DAD1 - Homo sapiens }\end{array}$ & 2.04 & 2.49E-09 & 2.56E-07 \\
\hline An02g14930* & $\begin{array}{l}\text { strong similarity to dolichyl-diphosphooligosaccharide- } \\
\text { protein glycotransferase gamma chain Ost3 - S. cerevisiae }\end{array}$ & 1.47 & $1.51 \mathrm{E}-06$ & 4.08E-05 \\
\hline An16g08570* & $\begin{array}{l}\text { strong similarity to translation initiation factor } 347 \mathrm{kDa} \\
\text { subunit stt3p - S. pombe }\end{array}$ & 1.78 & $2.74 \mathrm{E}-07$ & 1.07E-05 \\
\hline An 16g04330* & $\begin{array}{l}\text { strong similarity to mannose phospho-dolichol synthase } \\
\text { dpm } 1 \text { - Hypocrea jecorina }\end{array}$ & 1.63 & $2.72 \mathrm{E}-07$ & 1.07E-05 \\
\hline An01g05200* & strong similarity to DPM2 - Mus musculus & 1.43 & 4.84E-05 & $6.98 \mathrm{E}-04$ \\
\hline An03g04410* & $\begin{array}{l}\text { strong similarity to UDP-glucose:dolichyl-phosphate } \\
\text { glucosyltransferase Alg5 - S. cerevisiae }\end{array}$ & 1.78 & $3.47 \mathrm{E}-07$ & $1.26 \mathrm{E}-05$ \\
\hline An02g03240* & $\begin{array}{l}\text { strong similarity to UDP-N-acetylglucosamine-dolichyl- } \\
\text { phosphate N-acetylglucosaminephosphotransferase } \\
\text { Alg7 - S. cerevisiae }\end{array}$ & 1.92 & $1.76 \mathrm{E}-08$ & $1.24 \mathrm{E}-06$ \\
\hline An06g01100* & strong similarity to mannosyltransferase Alg1 - S. cerevisiae & 1.27 & $1.50 \mathrm{E}-04$ & $1.70 \mathrm{E}-03$ \\
\hline An14g05910* & strong similarity to mannosyltransferase Alg2 - S. cerevisiae & 1.93 & $2.28 \mathrm{E}-08$ & 1.53E-06 \\
\hline An18g05910* & $\begin{array}{l}\text { strong similarity to hypothetical glycosyl transferase } \\
\text { SPCC } 330.08 \text { - S. pombe }\end{array}$ & 1.49 & 7.14E-05 & 9.49E-04 \\
\hline An02g14940* & $\begin{array}{l}\text { strong similarity to human transmembrane protein } \\
\text { HTMPN-23 from patent WO9961471-A2 - Homo sapiens }\end{array}$ & 1.49 & $2.62 \mathrm{E}-06$ & $6.38 \mathrm{E}-05$ \\
\hline An04g03130 & $\begin{array}{l}\text { strong similarity to mannosylation protein Lec35 - } \\
\text { Cricetulus griseus [putative sequencing error] }\end{array}$ & 1.56 & 4.25E-07 & 1.46E-05 \\
\hline An18g02360* & $\begin{array}{l}\text { strong similarity to Dol-P-Man dependent alpha }(1-3) \\
\text { mannosyltransferase Alg3 - S. cerevisiae }\end{array}$ & 1.92 & $1.74 \mathrm{E}-08$ & $1.24 \mathrm{E}-06$ \\
\hline An08g07020* & similarity to mannosyl transferase Alg9 - S. cerevisiae & 1.48 & $7.80 \mathrm{E}-06$ & 1.53E-04 \\
\hline An01g08460* & strong similarity to the mannosyltransferase Alg12 - S. cerevisiae & 1.37 & 4.69E-04 & 4.36E-03 \\
\hline An02g12630* & strong similarity to glucosyltransferase Alg6 - S. cerevisiae & 1.37 & $1.35 \mathrm{E}-05$ & 2.44E-04 \\
\hline An04g08820* & strong similarity to glucosyltransferase Alg8 $-\mathrm{S}$. cerevisiae & 1.24 & $3.24 \mathrm{E}-04$ & $3.22 \mathrm{E}-03$ \\
\hline An02g02980* & $\begin{array}{l}\text { strong similarity to protein influencing Itr1 expression } \\
\text { Die2 - S.s cerevisiae }\end{array}$ & 1.42 & 4.53E-05 & $6.58 \mathrm{E}-04$ \\
\hline An $15 \mathrm{~g} 01420^{*}$ & strong similarity to glucosidase I Cwh41 - S. cerevisiae & 1.81 & $2.90 \mathrm{E}-08$ & 1.84E-06 \\
\hline An18g05620 & $\begin{array}{l}\text { strong similarity to glucosidase II alpha subunit } \\
\text { AAF66685.1 - Homo sapiens }\end{array}$ & 0.80 & 4.70E-04 & 4.37E-03 \\
\hline An01g10930* & $\begin{array}{l}\text { strong similarity to enzyme with sugar transferase activity } \\
\text { from patent JP11009276-A - Acremonium sp. }\end{array}$ & 0.45 & 2.27E-09 & 2.40E-07 \\
\hline An04g06920* & extracellular alpha-glucosidase aglU - Aspergillus niger & 0.60 & 7.55E-08 & 4.07E-06 \\
\hline An09g03300 & strong similarity to alpha-xylosidase XyIS - Sulfolobus solfataricus & 0.80 & 4.19E-04 & 3.98E-03 \\
\hline An09g05880* & strong similarity to alpha-glucosidase ModA - Dictyostelium discoideum & 1.75 & 4.77E-08 & 2.86E-06 \\
\hline An13g00620* & strong similarity to $80 \mathrm{~K}$ protein $\mathrm{H}$ precursor G19P1 - Homo sapiens & 1.53 & $1.24 \mathrm{E}-06$ & 3.47E-05 \\
\hline An07g06430* & strong similarity to glycoprotein glucosyltransferase & 1.64 & $3.96 \mathrm{E}-07$ & 1.39E-05 \\
\hline
\end{tabular}


Table 3 Differential expression of genes encoding secretory pathway related proteins (Continued)

\begin{tabular}{|c|c|c|c|c|}
\hline An01g12550 & $\begin{array}{l}\text { strong similarity to mannosyl-oligosaccharide 1,2-alpha- } \\
\text { mannosidase msdS - A. saitoi }\end{array}$ & 0.32 & $2.29 \mathrm{E}-11$ & $8.76 \mathrm{E}-09$ \\
\hline An06g01510 & $\begin{array}{l}\text { strong similarity to class I alpha-mannosidase } \\
\text { AAB62720.1 - Spodoptera frugiperda }\end{array}$ & 0.74 & 4.29E-05 & $6.31 \mathrm{E}-04$ \\
\hline An12g00340* & similarity to alpha 1,2-mannosidase IB - Homo sapiens & 1.54 & 7.61E-06 & $1.50 \mathrm{E}-04$ \\
\hline An05g01750 & strong similarity to alpha-1,6-mannosyltransferase Hoc1 - S. cerevisiae & 0.52 & $1.04 \mathrm{E}-08$ & 8.30E-07 \\
\hline An11g07490 & similarity to alpha-1,6-mannosyltransferase Hoc1 - S. cerevisiae & 0.66 & $8.04 \mathrm{E}-07$ & 2.46E-05 \\
\hline An15g03330 & strong similarity to galactosyltransferase Bed $1-$ S. cerevisiae & 1.42 & $9.62 \mathrm{E}-05$ & $1.20 \mathrm{E}-03$ \\
\hline An11g09890* & strong similarity to mannosyltransferase 1 PMT1 - Candida albicans & 1.36 & 1.27E-04 & 1.49E-03 \\
\hline An07g10350* & protein O-mannosyl transferase pmtA - A. niger & 1.50 & 4.45E-06 & $9.69 \mathrm{E}-05$ \\
\hline An16g08490* & $\begin{array}{l}\text { strong similarity to dolichyl-phosphate-D-mannose- } \\
\text { protein O-mannosyltransferase Pmt4 - S. cerevisiae }\end{array}$ & 1.49 & $1.89 \mathrm{E}-06$ & 4.90E-05 \\
\hline An15g04810 & similarity to alpha-1,3-mannosyltransferase Mnt2 - S. cerevisiae & 0.75 & $2.96 \mathrm{E}-05$ & 4.66E-04 \\
\hline An02g11720 & strong similarity to alpha-mannosidase $\mathrm{msd} 2-A$. nidulans & 0.71 & $1.64 \mathrm{E}-05$ & 2.85E-04 \\
\hline An01g06500 & strong similarity to filamentous growth protein Dfg5 - S. cerevisiae & 0.58 & 1.44E-05 & 2.56E-04 \\
\hline An02g02660 & strong similarity to hypothetical protein Dcw1 - S. cerevisiae & 0.78 & $2.74 \mathrm{E}-04$ & 2.79E-03 \\
\hline An11g01240* & similarity to filamentous growth protein Dfg5 - S. cerevisiae & 2.17 & $1.48 \mathrm{E}-08$ & 1.10E-06 \\
\hline \multicolumn{5}{|c|}{ Protein misfolding (UPR and ERAD associated degradation) } \\
\hline An08g00830 & $\begin{array}{l}\text { strong similarity to protein phosphatase type } 2 \mathrm{C} \\
\text { Ptc2 - S. cerevisiae }\end{array}$ & 1.31 & 5.07E-04 & 4.65E-03 \\
\hline An11g11250* & $\begin{array}{l}\text { strong similarity to interferon-induced double-stranded } \\
\text { RNA-activated protein kinase inhibitor P58 - Homo sapiens }\end{array}$ & 1.80 & $2.58 \mathrm{E}-07$ & $1.03 \mathrm{E}-05$ \\
\hline An01g14100* & weak similarity to stress protein Herp - Mus musculus & 1.61 & $1.12 \mathrm{E}-06$ & $3.21 \mathrm{E}-05$ \\
\hline An03g04340* & $\begin{array}{l}\text { strong similarity to ER membrane translocation facilitator } \\
\text { Sec61 - Yarrowia lipolytica }\end{array}$ & 1.68 & $9.76 \mathrm{E}-08$ & 4.9E-06 \\
\hline An04g00360* & $\begin{array}{l}\text { strong similarity to transport vesicle formation protein } \\
\text { Sec13 - S. cerevisiae }\end{array}$ & 1.84 & $1.28 \mathrm{E}-08$ & $9.9 \mathrm{E}-07$ \\
\hline An 15g00640* & $\begin{array}{l}\text { strong similarity to hypothetical protein GABA-A receptor } \\
\text { epsilon subunit - Caenorhabditis elegans }\end{array}$ & 2.03 & $6.20 \mathrm{E}-08$ & 3.53E-06 \\
\hline An16g07970* & similarity to autocrine motility factor receptor Amfr - Mus musculus & 1.60 & 1.09E-05 & $2.02 \mathrm{E}-04$ \\
\hline An12g00340* & similarity to alpha 1,2-mannosidase IB - Homo sapiens & 1.54 & 7.61E-06 & $1.50 \mathrm{E}-04$ \\
\hline An $15 \mathrm{~g} 01420^{*}$ & strong similarity to glucosidase I Cwh41 - S. cerevisiae & 1.81 & $2.90 \mathrm{E}-08$ & $1.84 \mathrm{E}-06$ \\
\hline An18g06220* & strong similarity to alpha-mannosidase Mns1 - S. cerevisiae & 2.10 & $3.47 \mathrm{E}-06$ & 8.05E-05 \\
\hline An01g12720* & $\begin{array}{l}\text { similarity to tumour suppressor protein TSA305 from } \\
\text { patent WO9928457-A1 - Homo sapiens }\end{array}$ & 1.69 & $3.91 \mathrm{E}-07$ & $1.38 \mathrm{E}-05$ \\
\hline \multicolumn{5}{|c|}{ Protein complex involved in protein transport } \\
\hline An01g03190 & similarity to protein Sec3 - S. cerevisiae & 1.30 & 7.93E-05 & 1.03E-03 \\
\hline An08g05570* & similarity to secretory protein Sec5 - S. cerevisiae & 1.54 & 1.97E-06 & 5.07E-05 \\
\hline An04g06180 & strong similarity to exocyst subunit Sec6 - S.s cerevisiae & 1.38 & 7.87E-05 & 1.03E-03 \\
\hline An08g07370 & similarity to exocyst protein Exo84 - S. cerevisiae & 1.42 & $9.83 \mathrm{E}-05$ & $1.22 \mathrm{E}-03$ \\
\hline An02g14400* & strong similarity to hypothetical protein SPCC338.13 - S. pombe & 1.43 & 8.59E-06 & $1.66 \mathrm{E}-04$ \\
\hline An16g01630 & $\begin{array}{l}\text { strong similarity to enoyl reductase of the lovastatin } \\
\text { biosynthesis lovC - A.terreus }\end{array}$ & 0.35 & $1.66 \mathrm{E}-10$ & 3.53E-08 \\
\hline An04g08690* & $\begin{array}{l}\text { similarity to polynucleotide sequence SEQ ID NO:3913 from } \\
\text { patent WO200058473-A2 - Homo sapiens }\end{array}$ & 1.37 & $7.88 \mathrm{E}-05$ & $1.03 \mathrm{E}-03$ \\
\hline An02g07090* & $\begin{array}{l}\text { strong similarity to ASNA1 product arsenite translocating } \\
\text { ATPase - Homo sapiens }\end{array}$ & 1.30 & 1.46E-04 & $1.66 \mathrm{E}-03$ \\
\hline An01g14250* & strong similarity to delta subunit of the coatomer delta-coat & 1.46 & $3.66 \mathrm{E}-06$ & $8.35 \mathrm{E}-05$ \\
\hline
\end{tabular}


Table 3 Differential expression of genes encoding secretory pathway related proteins (Continued)

\begin{tabular}{|c|c|c|c|c|}
\hline An08g01250* & weak similarity to COP1-interacting protein 7 CIP7 - Arabidopsis thaliana & 1.75 & 4.69E-07 & 1.57E-05 \\
\hline An16g05370* & similarity to zinc-finger protein Glo3 - S. cerevisiae & 1.59 & $1.28 \mathrm{E}-05$ & 2.34E-04 \\
\hline An $16 \mathrm{~g} 02460^{*}$ & $\begin{array}{l}\text { strong similarity to alpha subunit of the coatomer complex } \\
\text { Ret } 1 \text { - S. cerevisiae }\end{array}$ & 1.67 & $2.40 \mathrm{E}-07$ & $9.68 \mathrm{E}-06$ \\
\hline An01g14260* & $\begin{array}{l}\text { strong similarity to delta subunit of the coatomer delta-coat } \\
\text { protein CopD - Bos taurus [deleted ORF] }\end{array}$ & 1.51 & 1.15E-06 & 3.27E-05 \\
\hline An12g04830* & strong similarity to coatomer protein zeta chain Ret3 - S. cerevisiae & 1.47 & $7.15 \mathrm{E}-06$ & 1.44E-04 \\
\hline An07g06030* & strong similarity to coatomer gamma subunit 2 copg 2 - Homo sapiens & 1.65 & $4.32 \mathrm{E}-06$ & 9.45E-05 \\
\hline An02g05870* & $\begin{array}{l}\text { strong similarity to coatomer beta subunit copB2 - Homo sapiens } \\
\text { [putative frameshift] }\end{array}$ & 1.50 & 1.17E-04 & $1.40 \mathrm{E}-03$ \\
\hline An01g04040* & secretion-associated GTP-binding protein sarA - A. niger & 1.27 & $1.99 \mathrm{E}-04$ & 2.13E-03 \\
\hline An08g03270* & strong similarity to beta-COP Sec26 - S. cerevisiae & 1.48 & $2.84 \mathrm{E}-06$ & $6.82 \mathrm{E}-05$ \\
\hline An04g00360* & $\begin{array}{l}\text { strong similarity to transport vesicle formation protein } \\
\text { Sec13 - S. cerevisiae }\end{array}$ & 1.84 & $1.28 \mathrm{E}-08$ & $9.90 \mathrm{E}-07$ \\
\hline An02g01690* & $\begin{array}{l}\text { strong similarity to p150 component of the COPII coat of } \\
\text { secretory pathway vesicles Sec31 - S. cerevisiae }\end{array}$ & 1.60 & 2.05E-07 & 8.64E-06 \\
\hline An01g04730* & strong similarity to secretory protein $\operatorname{Sec} 23$ - S. cerevisiae & 1.62 & $2.83 \mathrm{E}-07$ & $1.08 \mathrm{E}-05$ \\
\hline An08g10650* & strong similarity to transport protein Sec24 - S. cerevisiae & 1.55 & $6.97 \mathrm{E}-07$ & $2.18 \mathrm{E}-05$ \\
\hline An16g03320* & strong similarity to transport protein Sec24A - Homo sapiens & 1.56 & $2.27 \mathrm{E}-06$ & $5.69 \mathrm{E}-05$ \\
\hline An15g01520* & $\begin{array}{l}\text { strong similarity to multidomain vesicle coat protein } \\
\text { Sec16 - S. cerevisiae }\end{array}$ & 1.53 & $1.74 \mathrm{E}-06$ & 4.55E-05 \\
\hline \multicolumn{5}{|c|}{ ER to Golgi and intra-Golgi transport } \\
\hline An08g03590* & strong similarity to precursor of protein Emp24 - S. cerevisiae & 1.39 & $7.73 \mathrm{E}-06$ & $1.52 \mathrm{E}-04$ \\
\hline An09g05490* & $\begin{array}{l}\text { strong similarity to COP-coated vesicle membrane protein } \\
\text { P24 homolog IbrA - Polysphondylium pallidum }\end{array}$ & 1.42 & $4.30 \mathrm{E}-06$ & 9.43E-05 \\
\hline An07g09160 & $\begin{array}{l}\text { strong similarity to pattern formation protein } \\
\text { cni - Drosophila melanogaster }\end{array}$ & 1.28 & $1.30 \mathrm{E}-04$ & $1.52 \mathrm{E}-03$ \\
\hline An01g08870* & $\begin{array}{l}\text { strong similarity to component of COPII-coated } \\
\text { vesicles Erv25 - S. cerevisiae }\end{array}$ & 1.39 & 7.23E-06 & 1.45E-04 \\
\hline An08g03960* & $\begin{array}{l}\text { strong similarity to hypothetical endoplasmic reticulum } \\
\text { associated protein - S. pombe }\end{array}$ & 1.55 & 7.36E-06 & 1.47E-04 \\
\hline An03g04940* & strong similarity to Erv41 - S. cerevisiae & 2.12 & $1.20 \mathrm{E}-08$ & $9.44 \mathrm{E}-07$ \\
\hline An01g04320* & $\begin{array}{l}\text { strong similarity to COPII vesicle coat component } \\
\text { protein Erv } 46 \text { - S. cerevisiae }\end{array}$ & 2.12 & 7.61E-09 & $6.57 \mathrm{E}-07$ \\
\hline An02g02830 & strong similarity to protein RER1 - Homo sapiens & 1.30 & $5.22 \mathrm{E}-05$ & 7.42E-04 \\
\hline An07g02190 & strong similarity to protein Sec7 - S. cerevisiae & 1.44 & $9.50 \mathrm{E}-06$ & $1.81 \mathrm{E}-04$ \\
\hline An08g06780* & strong similarity to transport protein Uso1 - S. cerevisiae & 1.52 & $2.93 \mathrm{E}-06$ & 7.00E-05 \\
\hline An18g06440 & strong similarity to COPII vesicle component Yip3 - S. cerevisiae & 1.67 & $2.58 \mathrm{E}-06$ & $6.30 \mathrm{E}-05$ \\
\hline An04g01780* & strong similarity to hypothetical protein YAR002c-a - S. cerevisiae & 1.54 & $1.03 \mathrm{E}-06$ & $3.00 \mathrm{E}-05$ \\
\hline An04g08830* & similarity to Golgi membrane protein Emp47 - S. cerevisiae & 1.69 & $9.30 \mathrm{E}-07$ & $2.78 \mathrm{E}-05$ \\
\hline An02g04250* & similarity to protein p58 - Rattus norvegicus & 1.77 & 2.01E-08 & $1.39 \mathrm{E}-06$ \\
\hline An04g01990* & similarity to protein ZW10 homolog HZW10 - Homo sapiens & 1.32 & $1.06 \mathrm{E}-04$ & $1.29 \mathrm{E}-03$ \\
\hline An04g06090 & $\begin{array}{l}\text { similarity to geranylgeranyltransferase type-II alpha } \\
\text { chain Bet4 - S. cerevisiae }\end{array}$ & 0.77 & $2.69 \mathrm{E}-04$ & 2.75E-03 \\
\hline An08g00290* & strong similarity to golgin-160 related protein Rud3 - S. cerevisiae & 1.52 & $1.11 \mathrm{E}-05$ & 2.05E-04 \\
\hline An08g06330* & strong similarity to epsilon-COP - Cricetulus griseus & 1.39 & $1.84 \mathrm{E}-05$ & $3.14 \mathrm{E}-04$ \\
\hline An07g07340* & strong similarity to luminal ER-protein retention & 1.65 & $2.00 \mathrm{E}-07$ & $8.46 \mathrm{E}-06$ \\
\hline
\end{tabular}


Table 3 Differential expression of genes encoding secretory pathway related proteins (Continued) Other processes in the secretory pathway

\begin{tabular}{|c|c|c|c|c|}
\hline An07g02170* & similarity to transport protein Bos $1-$ S. cerevisiae & 1.91 & 1.65E-08 & $1.18 \mathrm{E}-06$ \\
\hline An15g01380* & $\begin{array}{l}\text { strong similarity to Synaptobrevin homolog v-SNARE } \\
\text { Sec22 - S. cerevisiae }\end{array}$ & 1.30 & 2.74E-04 & $2.78 \mathrm{E}-03$ \\
\hline An 18g02490* & $\begin{array}{l}\text { strong similarity to ARF guanine-nucleotide exchange } \\
\text { factor } 2 \text { Gea2 - S. cerevisiae }\end{array}$ & 1.31 & $1.52 \mathrm{E}-04$ & $1.71 \mathrm{E}-03$ \\
\hline An07g08220* & strong similarity to clathrin associated epsin 2A - Homo sapiens & 1.39 & $1.58 \mathrm{E}-05$ & 2.76E-04 \\
\hline An02g08450* & secretory gene nsfA - Aspergillus niger & 1.27 & $2.86 \mathrm{E}-04$ & 2.89E-03 \\
\hline An02g14450* & secretory pathway Ca2+-ATPase pmrA - Aspergillus niger & 1.51 & $3.12 \mathrm{E}-06$ & 7.38E-05 \\
\hline An16g08470* & similarity to hypothetical cell growth regulator OS-9 - Homo sapiens & 1.76 & 8.57E-07 & $2.58 \mathrm{E}-05$ \\
\hline An02g03460* & similarity to hypothetical protein YIL041w - S. cerevisiae & 1.31 & $1.49 \mathrm{E}-04$ & $1.68 \mathrm{E}-03$ \\
\hline An04g02070 & strong similarity to clathrin heavy chain - Bos taurus & 1.30 & 1.09E-04 & 1.33E-03 \\
\hline An06g01200* & strong similarity to endosomal protein Emp70 - S. cerevisiae & 1.55 & $1.37 \mathrm{E}-06$ & 3.77E-05 \\
\hline An01g11960 & similarity to brefeldin A resistance protein $\mathrm{Bfr} 1-\mathrm{S}$. cerevisiae & 1.44 & $1.27 \mathrm{E}-05$ & 2.33E-04 \\
\hline An04g01950* & strong similarity to zinc-metalloprotease Ste24 - S. cerevisiae & 1.63 & $1.61 \mathrm{E}-07$ & 7.12E-06 \\
\hline
\end{tabular}

DSM code: ORF identifier in A. niger CBS 513.88 genome sequence [3]. Genes in bold are also found in maltose/xylose transcriptomic comparison [23]. ${ }^{*}$ Indicates genes that were also identified in strains with constitutively active hacA ${ }^{C A}[36]$.

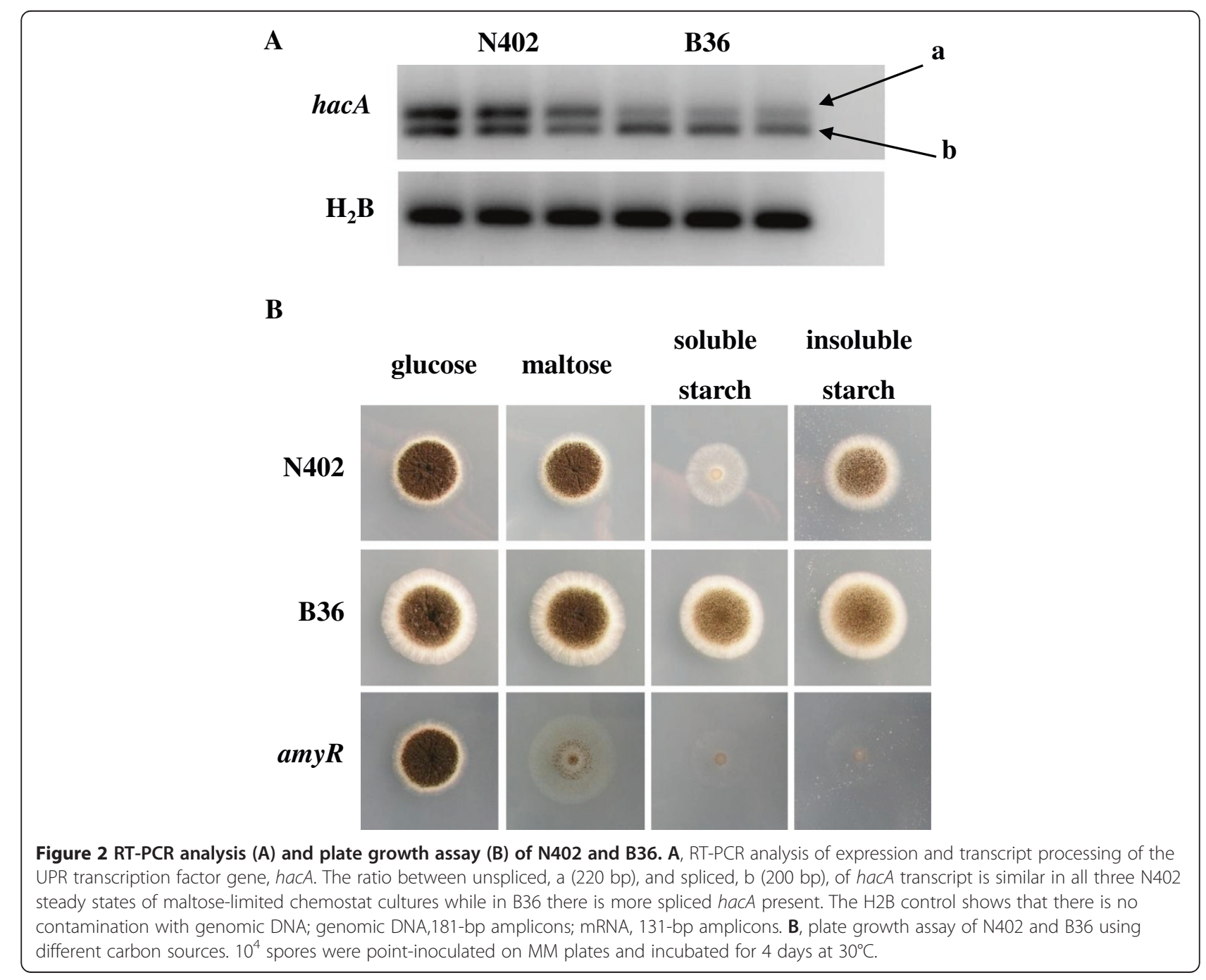


Table 4 Expression values of genes involved in starch metabolism

\begin{tabular}{|c|c|c|c|c|c|c|c|}
\hline Gene ID & Name & DSM annotation & N402 & B36 & Fold-change B36/N402 & $\mathbf{P}$ & FDR \\
\hline An04g06910 & amyR & $\begin{array}{l}\text { transcription factor of starch utilization } \\
\text { amyR - Aspergillus niger }\end{array}$ & 1176 & 748 & 0.64 & 1.06E-06 & $3.06 \mathrm{E}-05$ \\
\hline An11g03340 & $\operatorname{aamA}$ & acid alpha-amylase - Aspergillus niger & 3782 & 858 & 0.23 & $1.24 \mathrm{E}-09$ & $1.48 \mathrm{E}-07$ \\
\hline An04g06920 & $\operatorname{agd} A$ & $\begin{array}{l}\text { extracellular alpha-glucosidase } \\
\text { aglU - Aspergillus niger }\end{array}$ & 12052 & 7257 & 0.60 & 7.55E-08 & 4.07E-06 \\
\hline An01g10930 & $\operatorname{agd} B$ & $\begin{array}{l}\text { strong similarity to enzyme with sugar } \\
\text { transferase activity from patent } \\
\text { JP11009276-A - Acremonium sp. }\end{array}$ & 5808 & 2634 & 0.45 & 2.27E-09 & $2.40 \mathrm{E}-07$ \\
\hline An03g06550 & glaA & $\begin{array}{l}\text { glucan 1,4-alpha-glucosidase } \\
\text { glaA - Aspergillus niger }\end{array}$ & 21376 & 26346 & $1.23^{*}$ & $3.94 \mathrm{E}-04$ & $3.80 \mathrm{E}-03$ \\
\hline An04g06930 & amyc & $\begin{array}{l}\text { strong similarity to extracellular } \\
\text { alpha-amylase amyA } a m y B \text { - Aspergillus niger }\end{array}$ & 529 & 288 & 0.54 & $7.68 \mathrm{E}-08$ & 4.13E-06 \\
\hline An04g06920 & aglu & $\begin{array}{l}\text { extracellular alpha-glucosidase } \\
\text { aglU - Aspergillus niger }\end{array}$ & 12052 & 7257 & 0.60 & 7.55E-08 & 4.07E-06 \\
\hline An09g03100 & amyA & $\begin{array}{l}\text { strong similarity to alpha-amylase } \\
\text { precursor amy - Aspergillus niger }\end{array}$ & 359 & 115 & 0.32 & 7.34E-08 & 3.99E-06 \\
\hline
\end{tabular}

${ }^{*}$ Fold difference in glaA is under-estimated due to the saturation of array signals. Transcript level of glaA in B36 was about 7-fold higher than N402 based on qPCR results.

proteins [42-44]. In this context, it is interesting to note that protein secretion in $A$. fumigatus has most recently been shown to require controlled uptake of iron. Basically, the transcription factor PrtT not only positively regulates expression of protease genes but also strengthens expression of iron uptake genes [45]. We thus compared the published expression data of iron uptake genes in $A$. fumigatus (wt versus $\Delta p r t T$ ) with the expression data of their predicted orthologs in A. niger (B36 versus N402). Twelve out of 15 iron-uptake genes showed similar expression profiles (Additional file 5), i.e. their upregulation in wt versus $\Delta p r t T$ was mirrored in B36 versus N402. In agreement, expression profiles of the main iron transcription factors also matched, i.e. up-regulation/down-regulation of the activator HapX/repressor SreA in wt versus $\Delta$ prtT were comparably up-/downregulated in B36 versus N402. Hence, both independent observations from two Aspergilli strongly indicate that proper function of the protein secretion machinery and high fluxes through the secretory pathway mandate optimal iron supply and assuring proper ion homeostasis.

GO enrichment analysis of the down-regulated gene set in B36 uncovered three major categories: i) 'carbon catabolism, ii) 'amino acid catabolism', and iii) 'response to oxidative stress' (Additional file 3). The first two categories might be causatively linked to the RESS phenomenon discussed above, i.e. increased GlaA secretion is only possible at the cost of other secreted proteins. As AmyR targets related to starch degradation are down-regulated in B36 (see Table 4), processes related to polysaccharide degradation have consequently to be down-regulated as well. In a recent study, 19 proteases of $A$. niger were identified in the extracellular medium, when the strain was cultivated under sorbitol-, galacturonic acid- or carbon-starvation conditions [8]. Expression of 12 of them was reduced in B36 compared to N402, two of the genes were up-regulated and expression of five genes was unaltered (Additional file 6). Hence, overall reduction in protease activity in B36 will in turn decelerate amino acid catabolic processes. An additional explanation for reduced expression of carbon and amino acid catabolic processes is that many enzymes involved in these processes are iron-dependent. Iron deficiency has been shown to trigger a metabolic response in Saccharomyces cerevisiae or Schizosaccharomyces pombe, which includes down-regulation of enzymes involved in carbon and amino acid metabolism and respiration $[43,46-48]$. Assuming that this also holds true for $A$. niger, reduction in catabolic processes would lower the fluxes into the citric acid cycle and into the respiratory chain, which in turn would also lower the amount of radical oxygen species produced. Hence, oxidative stress would be diminished, which in turn would result in down-regulation of oxidative stress genes as observed in B36. A slight but significantly reduced RQ in B36 compared to N402 (Table 1) supports this hypothesis. Taken together, the enriched GO term set of down-regulated genes in B36 can hypothetically be viewed as a consequence of the RESS phenomenon and reduced iron availability due to increased GlaA secretion.

Two $A$. niger proteins lacking an N-terminal signal peptide for entering the secretory route were recently determined to be abundantly present in the secretome of $A$. niger [8]. It was thus proposed that proteins can also be exported out of the cell by the so-called nonclassical secretion pathway [8]. Interestingly, transcript 
levels of both protein-encoding genes were lowered in B36 versus N402 (An01g09980, fold-change B36/N402 = 0.15 , FDR $=8.65 \times 10^{-9}$; An01g00370, fold-change $=0.54$, FDR $=0.0001)$. This could mean that an accelerated activity of the classical secretory machinery is only possible at the expense of the non-classical secretion pathway which could be another potential example for the existence of the RESS regulatory feedback loop in A. niger.

\section{Comparison of the GlaA overexpression transcriptome with the maltose transcriptome}

In order to identify genes whose transcript levels are generally important for high-level secretion in A. niger, i.e. independent of the conditional trigger, we compared the GlaA transcriptomic fingerprint with two other recently determined fingerprints from our laboratory. First, we compared the GlaA overexpression transcriptome with the maltose transcriptome of $A$. niger. The maltose transcriptome was recently obtained by comparing carbon-limited chemostat cultures supplied with different carbon sources (maltose and xylose) but with the same specific growth rate $\left(D=0.16 h^{-1}\right)$ [23]. This comparison showed that the production rate of extracellular proteins was about three-fold higher in maltose-grown cultures compared to xylose [23]. As shown in the Venn diagram depicted in Figure 3, 150 genes were commonly induced in both B36 versus $\mathrm{N} 402$ and maltose versus xylose and thus represent the most interesting genes with respect to high-level secretion in A. niger. GO enrichment analysis of this set of genes confirmed that genes related to ER import, translocation, $\mathrm{N}$-glycosylation, and COPII transport are of utmost importance for ensuring high protein traffic through the secretory pathway (Additional file 7).

Genes that are induced in B36 versus N402, but not in maltose versus xylose, are likely to be genes that are mainly related to GlaA overexpression per se. There are 640 such genes and GO enrichment analysis uncovered two main categories (Additional file 7), one of which is the 'ion homeostasis' category, as expected due to the high iron, calcium and zinc demand for GlaA overexpression (see former section). The second category involves genes involved in 'DNA repair and DNA replication' and could hypothetically also be linked to the iron deficiency in B36 versus N402, as many proteins involved in nucleotide excision repair and DNA replication are iron-dependent [43]. Genes that induced in maltose versus xylose but not in B36 versus N402 are likely to be genes, which are important for starch/maltose degradation but not for xylose catabolism. Indeed, the enriched GO categories of this gene set (484 genes) contained 'starch metabolic processes' and other catabolic process related to 'carbon source oxidation', 'amino acid metabolism', and 'respiration and oxidative stress' (Additional file 7). These are processes important for (or related to) high ATP generation during oxidative phosphorylation in the respiratory chain and do likely form the energetic basis for the observed higher secretory flux in maltose cultures compared to xylose cultures despite similar growth rates. There were 146 commonly repressed genes in B36 versus N402 and in maltose versus xylose, but only a small fraction of these genes could be assigned to enriched GO terms related to 'saccharide catabolic processes' (Additional file 7).

\section{Comparison of the GlaA overexpression transcriptome with other high-secretion transcriptomes}

In order to determine so far unknown HacA targets and their involvement in UPR, we have recently determined the HacA transcriptome by expressing a constitutively active form of HacA (hac $A^{C A}$ ) in A. niger [36]. Using bioreactor-controlled batch cultures, we compared the genome-wide expression profiles of a strain expressing $h a c A^{C A}$ with a wild-type strain $\left(h a c A^{W T}\right)$ at three different time points during the exponential growth phase. At each of the three time points the up-regulated gene set of the $h a c A^{C A}$ cultures contained genes related to protein traffic through the secretory pathway, and to the UPR and ERAD response [36]. When comparing these data with the GlaA-overexpression transcriptome, one might expect a considerably overlap due to the fact that overexpression of GlaA induced splicing of the hacA
Induced genes

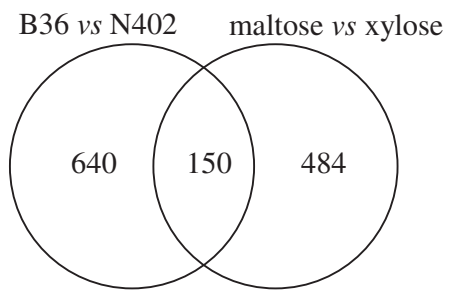

Repressed genes

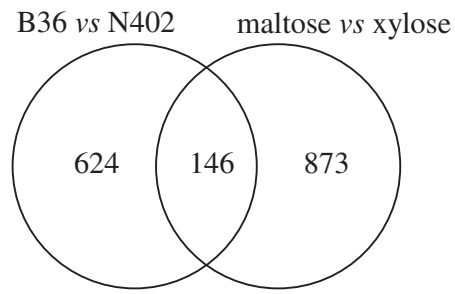

Figure 3 Venn diagrams of the number of overlapping and non-overlapping induced and repressed genes on B36/N402 and maltose/xylose [23] chemostat cultures. 
mRNA (Figure 2) and thus activation of HacA. Indeed, the transcriptional response in B36 had more in common with hacA ${ }^{C A}$ versus hac ${ }^{W T}$ (578 genes) than with maltose versus xylose (296 genes, data not shown). Commonly induced genes in B36 versus $\mathrm{N} 402$ and hacA ${ }^{C A}$ versus hacA ${ }^{W T}$ were predicted to function in 'vesicle coating'. 'targeting from the ER to the Golgi', 'N-glycosylation', and 'COPII transport'.

For a more condition-independent view on how the $A$. niger transcriptome ensures high-level secretion, we finally compared the transcriptomic dataset of seven independent studies performed with A. niger: i) the GlaAoverexpression transcriptome obtained from chemostat cultures of B36 versus N402 (this study), ii) the maltosehigh secretion transcriptome obtained from chemostat cultures of maltose versus xylose [23], iii) the HacA transcriptome reflecting permanent activation of UPR and obtained from batch cultures comparing hac $A^{\text {CA }}$ versus $h a c A^{W T}$ [36], and iv) three UPR stress transcriptomes obtained from $A$. niger batch cultures stressed with DTT, tunicamycin, or forced to express the heterologous protein t-PA [18].

This analysis uncovered 40 genes whose transcript levels were commonly modified under all seven secretion stress conditions: 36 genes were up-regulated, and 4 genes were down-regulated (Table 5). The genes from this set thus probably represent genes that are crucial for coping with stress conditions that target the secretion machinery. This gene set includes ER chaperones and foldases $(p r p A, \operatorname{clx} A, \operatorname{lhs} 1, p \operatorname{diA}, \operatorname{bip} A$, tigA), genes important for translocation of secretory proteins into the ER (sec63, sec11, sss1, spc3, sec71), and genes important for protein glycosylation and COPII-based vesicle trafficking (Table 5). Fascinatingly, a gene encoding the predicted acetyl-coenzyme A transporter (An02g13410) was consistently up-regulated under all seven conditions. In higher eukaryotes, this protein was shown to be involved in translocation of membrane-impermeable coenzyme A from the cytosol into the ER lumen, where it is used for transient acetylation of ER-based proteins, thus improving the folding efficiency of nascent secretory proteins [49]. It becomes therefore important to examine whether the predicted $A$. niger CoA transporter fulfills the same function. Similarly, the set of core genes included six hypothetical proteins, whose precise relevance for the secretory machinery remains to be elucidated in future studies.

\section{Conclusions}

The evidence is accumulating that the secretory machinery of $A$. niger is equiped with a high inherent flexibility, which enables the fungus to dynamically respond to changes in the secretory protein load. Irrespective of whether different amounts of a homologous protein or a heterologous protein have to be accommodated and escorted, or a specific step in the secretory pathway becomes blocked, A. niger follows general and specific strategies to adapt to these challenges. On the one hand, the burden of high protein loads is in general dealt with increased transcript levels of genes involved in stabilizing the secretory pathway, including chaperoneencoding and foldase-encoding genes, transport genes, and UPR- and ERAD-related genes. In addition, it seems likely that for the efficient secretion of individual proteins (either overexpressed or a heterologous proteins) an additional, particular set of genes becomes up-regulated, whose expression is important to deal with the specific requirements of the respective protein. On the other hand, $A$. niger attempts to avoid exceeding the maximum capacity of the secretory machinery. In doing so, the RESS regulatory system offers a flexible way to lower transcript levels of those genes whose function is less important for growth and survival under the given circumstances.

\section{Methods}

\section{Strains and inoculums}

The laboratory strain Aspergillus niger N402 [50] was used as a reference strain and B36 [26], which contains multiple copies of the glucoamylase gene, was used as an overproducer strain. Strains were grown on solidified Complete Medium (CM) containing 1\% ( $\left.\mathrm{w} \mathrm{v}^{-1}\right)$ glucose, $0.1 \%\left(\mathrm{w} \mathrm{v}^{-1}\right)$ casamino acids and $0.5 \%\left(\mathrm{w} \mathrm{v}^{-1}\right)$ yeast extract in addition to Minimal Medium (MM) [51]. Spore plates were incubated for four or five days at $30^{\circ} \mathrm{C}$ and stored for no more than three months at $4^{\circ} \mathrm{C}$. Conidia were harvested from CM agar plates with a sterile detergent solution containing $0.05 \%(\mathrm{w} / \mathrm{v})$ Tween 80 and $0.9 \%$ (w/v) $\mathrm{NaCl}$.

\section{Bioreactor cultivation conditions}

Maltose-limited batch and chemostat cultivations were performed as described previously for A. niger [23] with slight modifications. The N402 and B36 strains were both grown in triplicate in maltose-limited chemostat cultures.

\section{Batch cultures}

Batch cultivation was initiated by inoculation of $5 \mathrm{~kg}$ ammonium-based minimal medium with a conidial suspension to give $10^{9}$ conidia $\mathrm{L}^{-1}$. Maltose was heat sterilized separately from the MM and the final concentration was $0.8 \%(\mathrm{w} / \mathrm{v})$. Germination was induced by addition of $0.003 \%(\mathrm{w} / \mathrm{w})$ yeast extract. During the first six hours of cultivation the culture was aerated (air flow $=1 \mathrm{~L} \mathrm{~min}^{-1}$ ) through the headspace of the reactor and the stirrer speed was kept low at $250 \mathrm{rpm}$ to avoid loss of the hydrophobic conidia. After six hours when most 
Table 5 The list of common transcriptional response from all compared conditions

\begin{tabular}{|c|c|c|c|c|}
\hline DSM code & DSM annotation & Fold-change B36/N402 & $\mathbf{P}$ & FDR \\
\hline \multicolumn{5}{|c|}{ Protein folding } \\
\hline An01g13220 & similar to the chaperone Lhs1 & 2.26 & $1.34 \mathrm{E}-09$ & $1.58 \mathrm{E}-07$ \\
\hline An02g14800 & Protein disulfide isomerase PdiA & 1.72 & $5.98 \mathrm{E}-08$ & 3.43E-06 \\
\hline An01g04600 & Protein disulfide isomerase PrpA & 2.08 & 2.21E-09 & 2.40E-07 \\
\hline An01g08420 & calnexin ClxA & 2.42 & $8.96 \mathrm{E}-10$ & 1.13E-07 \\
\hline An11g04180 & chaperone BipA & 2.32 & $8.63 \mathrm{E}-10$ & $1.11 \mathrm{E}-07$ \\
\hline An16g07620 & similar to ER oxidising protein Ero1 & 1.97 & $1.02 \mathrm{E}-08$ & 8.15E-07 \\
\hline An18g02020 & Protein disulfide isomerase TigA & 1.89 & $1.61 \mathrm{E}-08$ & 1.17E-06 \\
\hline An11g11250 & similar to the chaperone P58IPK Homo sapiens & 1.80 & $2.58 \mathrm{E}-07$ & $1.03 \mathrm{E}-05$ \\
\hline \multicolumn{5}{|c|}{ Translocation/Signal peptidase complex } \\
\hline An01g13070 & similar to ER protein-translocation complex subunit SEC63 & 2.02 & 2.17E-08 & 1.47E-06 \\
\hline An16g08830 & similar to component of subcomplex SEC71 & 1.80 & $3.47 \mathrm{E}-08$ & 2.17E-06 \\
\hline An01g11630 & similar to translocation complex component SSS1 & 1.71 & $1.88 \mathrm{E}-07$ & $8.11 \mathrm{E}-06$ \\
\hline An09g05420 & similar to signal peptidase subunit SPC3 & 1.99 & $6.90 \mathrm{E}-09$ & $6.03 \mathrm{E}-07$ \\
\hline An01g00560 & similar to signal peptidase subunit SEC11 & 1.84 & $5.70 \mathrm{E}-07$ & $1.84 \mathrm{E}-05$ \\
\hline An15g06470 & similar to signal sequence receptor $a$-subunit & 1.86 & 4.49E-08 & $2.72 \mathrm{E}-06$ \\
\hline \multicolumn{5}{|l|}{ Glycosylation } \\
\hline An14g05910 & similar to mannosyltransferase ALG2 & 1.93 & $2.28 \mathrm{E}-08$ & $1.53 \mathrm{E}-06$ \\
\hline An03g04410 & similar to glucosyltransferase ALG5 & 1.78 & 3.47E-07 & $1.26 \mathrm{E}-05$ \\
\hline An02g03240 & similar to $\mathrm{N}$-acetylglucosaminephosphotransferase ALG7 & 1.92 & $1.76 \mathrm{E}-08$ & $1.24 \mathrm{E}-06$ \\
\hline An07g04190 & similar to glycosyltransferase WBP1 & 1.69 & $1.03 \mathrm{E}-07$ & 5.04E-06 \\
\hline An02g14560 & oligosaccharyltransferase alpha subunit OSTA & 2.05 & 2.27E-09 & 2.40E-07 \\
\hline An18g03920 & similar to oligosaccharyltransferase subunit OST2 & 2.04 & 2.49E-09 & 2.56E-07 \\
\hline An18g04260 & similar to UDP-galactose transporter HUT1 & 2.46 & $1.06 \mathrm{E}-09$ & $1.28 \mathrm{E}-07$ \\
\hline An13g00620 & similar to beta subunit of an ER alpha-glucosidase & 1.53 & $1.24 \mathrm{E}-06$ & 3.47E-05 \\
\hline An15g01420 & similar to glucosidase I CWH41 & 1.81 & $2.90 \mathrm{E}-08$ & 1.84E-06 \\
\hline An02g14940 & similar to flippase RFT1 & 1.49 & $2.62 \mathrm{E}-06$ & $6.38 \mathrm{E}-05$ \\
\hline \multicolumn{5}{|c|}{ Vesicle trafficking/transport } \\
\hline An03g04940 & similar to COPII vesicle coat component protein ERV41 & 2.12 & $1.20 \mathrm{E}-08$ & $9.44 \mathrm{E}-07$ \\
\hline An01g04320 & similar to COPII vesicle coat component protein ERV46 & 2.12 & 7.61E-09 & $6.57 \mathrm{E}-07$ \\
\hline An02g04250 & similar to ER protein P58 (lectin family) Rattus norvegicus & 1.77 & 2.01E-08 & 1.39E-06 \\
\hline An08g06780 & similar to ER to Golgi transport protein USO1 & 1.52 & 2.93E-06 & 7.00E-05 \\
\hline \multicolumn{5}{|c|}{ Lipid metabolism } \\
\hline An02g13410 & similar to acetyl-coenzyme A transporter AT-1 & 2.10 & 4.55E-09 & 4.23E-07 \\
\hline \multicolumn{5}{|l|}{ Stress related } \\
\hline An12g03580 & similar to glutathione S-transferase 3 MGST3 H. sapiens & 1.51 & $1.21 \mathrm{E}-05$ & 2.23E-04 \\
\hline An01g14100 & weakly similar to stress protein HERP Mus musculus & 1.61 & $1.12 \mathrm{E}-06$ & 3.21E-05 \\
\hline
\end{tabular}

$\begin{array}{llrr}\text { An01g08170 similar to DNA repair endonuclease RAD1 S. pombe } & 2.05 & 1.62 \mathrm{E}-08\end{array}$

Phosphate metabolism

An12g01910 similar to phytase PHYA3 Aspergillus fumigatus

0.56

2.09E-07

8.76E-06

\section{Cell rescue. Defense and virulence}


Table 5 The list of common transcriptional response from all compared conditions (Continued)

\begin{tabular}{llll}
\hline Unclassified & & & \\
An08g03960 & hypothetical endoplasmic reticulum associated protein & 1.55 & $7.36 \mathrm{E}-06$ \\
An08g03970 & hypothetical protein & 1.87 & $1.47 \mathrm{E}-04$ \\
An07g10280 & hypothetical protein & 1.43 & $1.83 \mathrm{E}-06$ \\
An09g06130 & hypothetical protein & 1.64 & $6.40 \mathrm{E}-06$ \\
An18g01000 & hypothetical protein & 0.56 & $1.31 \mathrm{E}-04$ \\
An13g01520 & hypothetical protein & 0.49 & $1.46 \mathrm{E}-05$ \\
\hline
\end{tabular}

DSM code: ORF identifier in A. niger CBS 513.88 genome sequence [3]. The list of common transcriptional response from B36/N402 (this study), maltose/xylose [23], hacA ${ }^{C A} / h_{a c A}{ }^{W T}$ [36] and ER stress with at least 2 types of protein folding stress [18].

conidia had germinated, air was sparged into the culture broth, mixing was intensified $(750 \mathrm{rpm})$ for more efficient oxygen transfer, and $0.01 \%(\mathrm{v} / \mathrm{v})$ of polypropylene glycol (PPG) was added as an antifoaming agent. The temperature was $30^{\circ} \mathrm{C}$ and the $\mathrm{pH}$ was kept constant at $\mathrm{pH}=3$ by computer-controlled addition of $2 \mathrm{M} \mathrm{NaOH}$ or $1 \mathrm{M} \mathrm{HCl}$. Acidification of the culture broth was used as an indirect growth measurement [52]. Submerged cultivation was performed with 6.6 L BioFlo3000 bioreactors (New Brunswick Scientific, NJ, USA).

\section{Chemostat cultures}

Continuous cultivation was started in the lateexponential growth phase, when $90 \mathrm{mmol}$ of $\mathrm{NaOH}$ had been added to the batch culture (75\% of maltose had been consumed, at a biomass concentration of about 3.5 $\mathrm{g}$ dry weight per $\mathrm{kg}$ of culture). The dilution rate (D) was set at $0.1 \mathrm{~h}^{-1}$. Steady-states, where the specific growth rate $(\mu)$ is equal to the dilution rate, were defined by constant alkali addition rate and constant $\mathrm{CO}_{2}, \mathrm{O}_{2}$ and biomass concentrations after four residence times $(\approx 40 \mathrm{~h})$. Samples were taken regularly to monitor growth and to determine if a steady-state had been reached. All samples were quickly frozen in liquid nitrogen. Mycelium harvested during steady-state conditions was used for micro-array analysis.

\section{Analysis of culture broth}

Dry weight biomass concentration was determined by weighing lyophilized mycelium separated from a known mass of culture broth. Culture broth was filtered through GF/C glass microfiber filters (Whatman). The filtrate was collected and frozen for use in solute analyses. The mycelium was washed with demineralised water, rapidly frozen in liquid nitrogen, and stored at $-80^{\circ} \mathrm{C}$ until lyophilization. Extracellular protein concentration was determined using the Quick Start Bradford Protein Assay (Bio-Rad) with BSA as a standard. The total organic carbon in the culture filtrate was measured with a Total Organic Carbon Analyzer (TOC-Vcsn; Shimadzu, Japan), using glucose as a standard.

\section{RNA isolation and quality control}

Total RNA was extracted by modified Trizol extraction. Frozen ground mycelium $(\approx 200 \mathrm{mg}$ ) was directly suspended in $800 \mu \mathrm{l}$ Trizol reagent (Invitrogen) and vortexed vigorously for $1 \mathrm{~min}$. After centrifugation for 5 min at $13000 \mathrm{rpm}, 450 \mu \mathrm{l}$ of the supernatant was transferred to a new tube. Chloroform $(150 \mu \mathrm{l})$ was added and after $3 \mathrm{~min}$ incubation at room temperature, samples were spun down for $15 \mathrm{~min}$ at maximum speed. The upper aqueous phase was transferred to a new tube to which $400 \mu \mathrm{l}$ of isopropanol was added, followed by $10 \mathrm{~min}$ incubation at room temperature and centrifugation for $10 \mathrm{~min}$ at $13000 \mathrm{rpm}$. Pellet was washed with $75 \%$ ethanol and finally precipitated in $100 \mu \mathrm{l} \mathrm{H}_{2} \mathrm{O}$. RNA samples for micro-array analysis were additionally purified on NucleoSpin RNA II columns (Machery-Nagel) according to manufacturer's instructions. RNA quantity and quality was determined on Nanodrop spectrophotometer.

\section{Microarray analysis}

Probe synthesis and fragmentation were performed at ServiceXS (Leiden, The Netherlands) according to the GeneChip Expression Analysis Technical Manual (Affymetrix inc., 2002). DSM (Delft, The Netherlands) proprietary $A$. niger gene chips were hybridized, washed, stained and scanned as described in the GeneChip Expression Analysis Technical Manual (Affymetrix inc., 2002).

\section{Normalization, filtering, statistical significance, and comparisons}

Transcriptomic analysis was basically performed using Bioconductor and statistical programming language $\mathrm{R}$ [53]. Two experimental conditions (N402 vs B36) were compared to each other; each condition was represented by independent triplicate cultures. Using the robust multi-array analysis (RMA) package [54], background correction, normalization and probe summarization steps were performed according to the default setting of the RMA package. Differential gene expression was evaluated by moderated $t$-statistics using the Limma package 
[55] with a threshold of the Benjamini and Hochberg (BH) False Discovery Rate (FDR) [56] at 0.005. A minimal fold-change criterion was not applied for the identification of differentially expressed genes, as fold-changes are not necessarily related to biological relevance $[57,58]$. Fold-changes of gene expression from N402 to B36 (B36/N402) were calculated from normalized expression values. Means of the expression values for B36 and N402 as well as classifiers for the moderated tstatistics are summarized in Additional file 1.

\section{Gene ontology (GO) and enrichment analysis}

Controlling the FDR at $\mathrm{q}<0.05$, over-represented $\mathrm{GO}$ terms in sets of differentially expressed genes were determined by Fisher's exact test [59]. An improved GO annotation for the $A$. niger CBS513.88 was applied that is based on ontology mappings from A.nidulans FGSCA4 (http://www.broadinstitute.org/fetgoat/index. html) [29].

\section{Quantitative real-time PCR (qPCR)}

Quantitative real-time PCR was performed as described [60] with slight modifications. After a DNAse treatment (DNA-freeTM Kit Applied Biosystems) of $10 \mu \mathrm{g}$ of total RNA, 600 ng were used for cDNA synthesis using the iScriptTM cDNA Synthesis Kit from BioRad according to the manufactures instructions. Real time PCR was performed in PTC-200 Peltier Thermal Cycler with a Chromo4 Continuous Fluorescence detection system from Bio-Rad with a SYBRgreen mix $\left(\mathrm{iQ}^{\mathrm{Tm}} \mathrm{SYBR}^{\circledR}\right.$ Green supermix) in a volume of $25 \mu \mathrm{l}$. Each reaction was carried out in triplicate with $\sim 200 \mathrm{ng}$ of cDNA and each oligonucleotide primer at $0.3 \mu \mathrm{M}$. Oligonucleotide primers used for real time PCR are listed in Additional file 8. Two reference genes, $\mathrm{H} 2 \mathrm{~B}$ and Cox 5 were used for normalization. The PCR program was as follows: $95^{\circ} \mathrm{C}$ for $3 \mathrm{~min}$, followed by 39 cycles of $95^{\circ} \mathrm{C}$ for $15 \mathrm{sec}$ and $60^{\circ} \mathrm{C}$ for $1 \mathrm{~min}$, followed by a melting curve analysis. The efficiency of each primer pair and mean $\mathrm{Ct}$ (threshold cycles) values were calculated and used for determination of glucoamylase RNA transcript levels [61]. Estimation of glucoamylase gene copy number was also performed by qPCR as well but with genomic DNA as a template.

\section{Analysis of glucoamylase activity}

One unit of glucoamylase activity was expressed as the amount of enzyme that liberates one micromole of glucose per minute from starch. Filtrates from steady-state cultures were mixed with $1 \%$ soluble starch (Sigma, S9765) in $50 \mathrm{mM} \mathrm{NaAc}$ buffer at $\mathrm{pH} 4.5$ and incubated at $37^{\circ} \mathrm{C}$ for $3.75 \mathrm{~min}$. Liberated glucose was determined with the glucose kit from ABX (Pentra Glucose HK CP).

\section{Western blot analysis of glucoamylase}

Protein concentrations of the samples were determined with the Bradford assay using BSA as a standard. For each sample, culture filtrate samples corrected for equal amounts of biomass were mixed with $2 x$ loading buffer (0.5 M HCl, 25\% glycerol, 10\% SDS, 0.5\% bromophenol blue, 5\% $\beta$-mercaptoethanol) and boiled for $5 \mathrm{~min}$ at $95^{\circ} \mathrm{C}$. Protein samples were loaded on 9\% SDS-PAGE gels and blotted to a nitrocellulose membrane through semi-dry electrotransfer. The membrane was blocked for $1 \mathrm{~h}$ with 5\% low-fat dried milk in TPBS (PBS, 0.05\% Tween20) and glucoamylase protein was detected using a glucoamylase-specific primary antibody $(1: 3,000)$ for 1 $\mathrm{h}$ at room temperature, followed by a goat anti-mouseHRP secondary antibody (1:20,000) for $1 \mathrm{~h}$ at room temperature. Detection was performed using a chemiluminescence kit (Bio-Rad) according to the manufacturer's instructions. Analysis and quantification of band intensities were performed using Image J software based on N402 signal as one.

\section{Additional files}

Additional file 1: Differentially expressed genes between B36 and N402 maltose-limited chemostat cultures.

Additional file 2: Network map based on GO-enrichment analysis using the differentially expressed, induced, and repressed gene sets in B36/N402 chemostat cultures.

Additional file 3: Enriched-GO terms using the differentially expressed, induced, and repressed gene sets in B36/N402 chemostat cultures.

Additional file 4: Four higher-order categories of enriched-GO terms using the induced gene set in B36/N402 chemostat cultures.

Additional file 5: Expression values of iron uptake genes.

Additional file 6: Expression values of protease genes.

Additional file 7: Enriched-GO terms from the comparison between B36/N402 versus maltose/xylose.

Additional file 8: Primers used in qPCR and RT PCR.

Competing interests

The authors declare that they have no competing interests.

\section{Authors' contributions}

MJK, TRJ, MA, and JP performed the chemostat experiments. MJK carried out the physiological and transcriptomic analyses and drafted the manuscript. BMN participated in initial transcriptomic analyses and the statistical analysis. MJK, VM and AFJR were involved in writing the manuscript. MJK, TRJ, VM and AFJR designed the experiments and interpreted the results. All authors read and approved the final manuscript.

\section{Acknowledgements}

The authors would like to acknowledge Nick van Biezen in HAN BioCentre for glucoamylase activity analysis. We are grateful to Peter Punt (TNO, The Netherlands) for kindly providing the B36 strain and helpful discussions. We thank David Archer and Frans Klis for critically reading the manuscript and their helpful comments. This project was carried out within the research programme of the Kluyver Centre for Genomics of Industrial Fermentation which is part of the Netherlands Genomics Initiative/Netherlands

Organization for Scientific Research. 


\section{Author details}

${ }^{1}$ Department Molecular Microbiology and Biotechnology, Institute of Biology Leiden, Leiden University, Sylviusweg 72, 2333 BE, Leiden, The Netherlands. ${ }^{2}$ Kluyver Centre for Genomics of Industrial Fermentation, P.O. Box 50572600 GA, Delft, The Netherlands. ${ }^{3}$ Novo Nordisk, Protein Expression, 2760, Måløv, Denmark. ${ }^{4}$ Institute of Biotechnology, Department Applied and Molecular Microbiology, Berlin University of Technology, Gustav-Meyer-Allee 25, 13355, Berlin, Germany.

Received: 6 July 2012 Accepted: 6 December 2012

Published: 13 December 2012

\section{References}

1. Meyer $\mathrm{V}$ : Genetic engineering of filamentous fungi-progress, obstacles and future trends. Biotechnol Adv 2008, 26(2):177-185.

2. Meyer V, Wu B, Ram AF: Aspergillus as a multi-purpose cell factory: current status and perspectives. Biotechnol Lett 2010, 33(3):469-476.

3. Pel HJ, de Winde JH, Archer DB, Dyer PS, Hofmann G, Schaap PJ, Turner G, de Vries RP, Albang R, Albermann K, et al: Genome sequencing and analysis of the versatile cell factory Aspergillus niger CBS 513.88. Nat Biotechnol 2007, 25(2):221-231.

4. Meyer V, Arentshorst M, El-Ghezal A, Drews AC, Kooistra R, van den Honde CA, Ram AF: Highly efficient gene targeting in the Aspergillus niger kus $A$ mutant. J Biotechnol 2007, 128(4):770-775.

5. Fleissner A, Dersch P: Expression and export: recombinant protein production systems for Aspergillus. Appl Microbiol Biotechnol 2010, 87(4):1255-1270.

6. de Souza WR, de Gouvea PF, Savoldi M, Malavazi I, de Souza Bernardes LA Goldman MH, de Vries RP, de Castro Oliveira JV, Goldman GH: Transcriptome analysis of Aspergillus niger grown on sugarcane bagasse. Biotechnol Biofuels 2011, 4:40.

7. Adav SS, Li AA, Manavalan A, Punt P, Sze SK: Quantitative iTRAQ secretome analysis of Aspergillus niger reveals novel hydrolytic enzymes. J Proteome Res 2010, 9(8):3932-3940.

8. Braaksma M, Martens-Uzunova ES, Punt PJ, Schaap PJ: An inventory of the Aspergillus niger secretome by combining in silico predictions with shotgun proteomics data. BMC Genomics 2010, 11:584

9. de Oliveira JM, van Passel MW, Schaap PJ, de Graaff LH: Proteomic analysis of the secretory response of Aspergillus niger to D-maltose and D-xylose. PLoS One 2011, 6(6):e20865.

10. Lu X, Sun J, Nimtz M, Wissing J, Zeng AP, Rinas U: The intra- and extracellular proteome of Aspergillus niger growing on defined medium with xylose or maltose as carbon substrate. Microb Cell Fact 2010, 9:23.

11. Mach-Aigner AR, Omony J, Jovanovic B, van Boxtel AJ, de Graaff LH: D-xylose concentration-dependent Hydrolase Expression Profiles and the Role of CreA and XInR in A. niger. Appl Environ Microbiol 2012, 78(9):3145-3155.

12. Yuan XL, Goosen C, Kools $\mathrm{H}$, van der Maarel MJ, van den Hondel CA Dijkhuizen L, Ram AF: Database mining and transcriptional analysis of genes encoding inulin-modifying enzymes of Aspergillus niger. Microbiology 2006, 152(Pt 10):3061-3073.

13. Tsukagoshi N, Kobayashi T, Kato M: Regulation of the amylolytic and (hemi-)cellulolytic genes in Aspergilli. J Gen Appl Microbiol 2001, 47(1):1-19.

14. Romisch K: Surfing the Sec61 channel: bidirectional protein translocation across the ER membrane. J Cell Sci 1999, 112(Pt 23):4185-4191.

15. Maattanen P, Gehring K, Bergeron JJ, Thomas DY: Protein quality control in the ER: the recognition of misfolded proteins. Semin Cell Dev Biol 2010, 21(5):500-511.

16. Geysens S, Whyteside G, Archer DB: Genomics of protein folding in the endoplasmic reticulum, secretion stress and glycosylation in the Aspergilli. Fungal Genet Biol 2009, 46(1):S121-S140

17. Mulder HJ, Saloheimo M, Penttila M, Madrid SM: The transcription factor HACA mediates the unfolded protein response in Aspergillus niger, and up-regulates its own transcription. Mol Genet Genomics 2004, 271(2):130-140.

18. Guillemette $T$, van Peij NN, Goosen $T$, Lanthaler $K$, Robson GD, van den Hondel CA, Stam H, Archer DB: Genomic analysis of the secretion stress response in the enzyme-producing cell factory Aspergillus niger. BMC Genomics 2007, 8:158.
19. Saloheimo M, Pakula TM: The cargo and the transport system: secreted proteins and protein secretion in Trichoderma reesei (Hypocrea jecorina). Microbiology 2012, 158(Pt 1):46-57.

20. Saloheimo M, Valkonen $M$, Penttila M: Activation mechanisms of the HAC1-mediated unfolded protein response in filamentous fungi. Mol Microbiol 2003, 47(4):1149-1161.

21. Yoshida H, Matsui T, Yamamoto A, Okada T, Mori K: XBP1 mRNA Is Induced by ATF6 and Spliced by IRE1 in Response to ER Stress to Produce a Highly Active Transcription Factor. Cell 2001, 107(7):881-891.

22. Kaufman RJ: Stress signaling from the lumen of the endoplasmic reticulum: coordination of gene transcriptional and translational controls. Genes Dev 1999, 13(10):1211-1233.

23. Jorgensen TR, Goosen T, Hondel CA, Ram AF, Iversen JJ: Transcriptomic comparison of Aspergillus niger growing on two different sugars reveals coordinated regulation of the secretory pathway. BMC Genomics 2009, 10:44.

24. Carvalho NDSP, Arentshorst M, Kooistra R, Stam H, Sagt CM, van den Hondel CAMJJ, Ram AFJ: Effects of a defective ERAD pathway on growth and heterologous protein production in Aspergillus niger. Appl Microbiol Biotechnol 2011, 89(2):357-373.

25. Kumar $P$, Satyanarayana T: Microbial glucoamylases: characteristics and applications. Crit Rev Biotechnol 2009, 29(3):225-255.

26. Verdoes JC, Punt PJ, Schrickx JM, Vanverseveld HW, Stouthamer AH, Vandenhondel CAMJJ: Glucoamylase Overexpression in Aspergillus niger Molecular Genetic-Analysis of Strains Containing Multiple Copies of the glaA-gene. Transgenic Res 1993, 2(2):84-92.

27. Verdoes JC, Vandiepeningen AD, Punt PJ, Debets AJM, Stouthamer AH, Vandenhondel CAMJJ: Evaluation of Molecular and Genetic Approaches to Generate Glucoamylase Overproducing Strains of Aspergillus niger. J Biotechnol 1994, 36(2):165-175.

28. Finkelstein DB, Rambosek J, Crawford MS, Soliday CL, MCAda PC, Leach J: Protein secretion in Aspergillus niger. In Genetics and Molecular Biology of Industrial Microorganisms. Edited by Hershberger CL, Queener SW, Hegeman G. Washington, DC: Am. Soc. Microbiol; 1989:295-300.

29. Nitsche BM, Crabtree J, Cerqueira GC, Meyer V, Ram AF, Wortman JR: New resources for functional analysis of omics data for the genus Aspergillus. BMC Genomics 2011, 12:486.

30. van Gemeren IA, Punt PJ, Drint-Kuyvenhoven A, Broekhuijsen MP, Van't Hoog A, Beijersbergen A, Verrips CT, Van den Hondel CA: The ER chaperone encoding bipA gene of black Aspergilli is induced by heat shock and unfolded proteins. Gene 1997, 198(1-2):43-52.

31. Punt PJ, van Gemeren IA, Drint-Kuijvenhoven J, Hessing JG, van MuijlwijkHarteveld GM, Beijersbergen A, Verrips CT, van den Hondel CA: Analysis of the role of the gene bipA, encoding the major endoplasmic reticulum chaperone protein in the secretion of homologous and heterologous proteins in black Aspergilli. Appl Microbiol Biotechnol 1998, 50(4):447-454.

32. Guillemette T, Ram AF, Carvalho ND, Joubert A, Simoneau P, Archer DB: Methods for investigating the UPR in filamentous fungi. Methods Enzymol 2011, 490:1-29.

33. Yuan $X L$, van der Kaaij $R M$, van den Hondel CAMJJ, Punt PJ, van der Maarel MJEC, Dijkhuizen L, Ram AFJ: Aspergillus niger genome-wide analysis reveals a large number of novel alpha-glucan acting enzymes with unexpected expression profiles. Mol Genet Genomics 2008, 279(6):545-561.

34. Pakula TM, Laxell M, Huuskonen A, Uusitalo J, Saloheimo M, Penttila M: The effects of drugs inhibiting protein secretion in the filamentous fungus Trichoderma reesei - Evidence for down-regulation of genes that encode secreted proteins in the stressed cells. J Bio/ Chem 2003, 278(45):45011-45020.

35. Martinez IM, Chrispeels MJ: Genomic analysis of the unfolded protein response in Arabidopsis shows its connection to important cellular processes. Plant Cell 2003, 15(2):561-576.

36. Carvalho ND, Jørgensen TR, Arentshorst M, Nitsche BM, Hondel CA, Archer DB, Ram AF: Genome-wide expression analysis upon constitutive activation of the HacA bZIP transcription factor in Aspergillus niger reveals a coordinated cellular response to counteract ER stress. BMC Genomics 2012, 30(13):350.

37. Sorimachi K, Jacks AJ, Le Gal-Coeffet MF, Williamson G, Archer DB, Williamson MP: Solution structure of the granular starch binding domain of glucoamylase from Aspergillus niger by nuclear magnetic resonance spectroscopy. J Mol Biol 1996, 259(5):970-987.

38. Lee J, Paetzel M: Structure of the catalytic domain of glucoamylase from Aspergillus niger. Acta Crystallogr Sect F Struct Biol Cryst Commun 2011 67(Pt 2):188-192. 
39. Solovyov A, Gilbert HF: Zinc-dependent dimerization of the folding catalyst, protein disulfide isomerase. Protein Sci 2004, 13(7):1902-1907.

40. Wang H, Entwistle J, Morlon E, Archer DB, Peberdy JF, Ward M, Jeenes DJ: Isolation and characterisation of a calnexin homologue, $\mathrm{ClxA}$, from Aspergillus niger. Mol Genet Genomics 2003, 268(5):684-691.

41. Dolman NJ, Tepikin AV: Calcium gradients and the Golgi. Cell Calcium 2006, 40(5-6):505-512.

42. Stojilkovic SS: Ca2+-regulated exocytosis and SNARE function. Trends Endocrinol Metab 2005, 16(3):81-83.

43. Lill R: Function and biogenesis of iron-sulphur proteins. Nature 2009, 460(7257):831-838.

44. Waldron KJ, Rutherford JC, Ford D, Robinson NJ: Metalloproteins and metal sensing. Nature 2009, 460(7257):823-830.

45. Hagag S, Kubitschek-Barreira P, Neves GW, Amar D, Nierman W, Shalit I, Shamir R, Lopes-Bezerra L, Osherov N: Transcriptional and proteomic analysis of the Aspergillus fumigatus $\Delta$ prtT protease-deficient mutant. PLoS One 2012, 7(4):e33604.

46. Mercier A, Labbe S: Iron-dependent remodeling of fungal metabolic pathways associated with ferrichrome biosynthesis. Appl Environ Microbiol 2010, 76(12):3806-3817.

47. Philpott CC, Protchenko O: Response to iron deprivation in Saccharomyces cerevisiae. Eukaryot Cell 2008, 7(1):20-27.

48. Philpott CC, Leidgens S, Frey AG: Metabolic remodeling in iron-deficient fungi. Biochim Biophys Acta 2012, 1823(9):1509-1520

49. Jonas MC, Pehar M, Puglielli L: AT-1 is the ER membrane acetyl-CoA transporter and is essential for cell viability. J Cell Sci 2010, 123(Pt 19):3378-3388.

50. Bos CJ, Debets AJ, Swart K, Huybers A, Kobus G, Slakhorst SM: Genetic analysis and the construction of master strains for assignment of genes to six linkage groups in Aspergillus niger. Curr Genet 1988, 14(5):437-443.

51. Bennett JW, Lasure LL: More gene manipulations in fungi. San Diego: Academic Press; 1991:441-447.

52. Iversen JJL, Thomsen JK, Cox RP: On Line Growth Measurements in Bioreactors by Titrating Metabolic Proton-Exchange. App/ Microbiol Biotechnol 1994, 42(2-3):256-262.

53. Nitsche BM, Ram AF, Meyer $\mathrm{V}$ : The use of open source bioinformatics tools to dissect transcriptomic data. Methods Mol Biol 2012, 835:311-331.

54. Irizarry RA, Bolstad BM, Collin F, Cope LM, Hobbs B, Speed TP: Summaries of affymetrix GeneChip probe level data. Nucleic Acids Res 2003, 31(4):e15.

55. Smyth GK: Linear models and empirical bayes methods for assessing differential expression in microarray experiments. Stat Appl Genet Mol Biol 2004, 3:Article3.

56. Benjamini $Y$, Hochberg $Y$ : Controlling the False Discovery Rate - a Practical and Powerful Approach to Multiple Testing. J Roy Stat Soc B 1995, 57(1):289-300.

57. van den Berg RA, Hoefsloot HC, Westerhuis JA, Smilde AK, van der Werf MJ: Centering, scaling, and transformations: improving the biological information content of metabolomics data. BMC Genomics 2006, 7:142.

58. van den Berg RA, Braaksma $M$, van der Veen $D$, van der Werf MJ, Punt PJ, van der Oost J, de Graaff LH: Identification of modules in Aspergillus niger by gene co-expression network analysis. Fungal Genet Biol 2010, 47(6):539-550.

59. Fisher RA: On the interpretation of $\mathrm{X} 2$ from contingency tables, and the calculation of P. J Roy Stat Soc B 1922, 85(1):87-94.

60. Nowrousian M, Ringelberg C, Dunlap JC, Loros JL, Kuck U: Cross-species microarray hybridization to identify developmentally regulated genes in the filamentous fungus Sordaria macrospora. Mol Genet Genomics 2005, 273(2):137-149.

61. Pfaffl MW: A new mathematical model for relative quantification in real-time RT-PCR. Nucleic Acids Res 2001, 29(9):e45.

doi:10.1186/1471-2164-13-701

Cite this article as: Kwon et al:: The transcriptomic fingerprint of glucoamylase over-expression in Aspergillus niger. BMC Genomics 2012 13:701

\section{Submit your next manuscript to BioMed Central and take full advantage of:}

- Convenient online submission

- Thorough peer review

- No space constraints or color figure charges

- Immediate publication on acceptance

- Inclusion in PubMed, CAS, Scopus and Google Scholar

- Research which is freely available for redistribution

Submit your manuscript at www.biomedcentral.com/submit
Ciomed Central 